Reynolds, D. W., T. Coleman, D. J. Gottas, and T. LeFebvre, 2016: Utilization of real-time vineyard observations to produce downscaled temperature forecasts for frost protection operations. J. Operational Meteor., 4 (1), 1-21, doi: http://dx.doi.org/10.15191/nwajom.2016.0401.

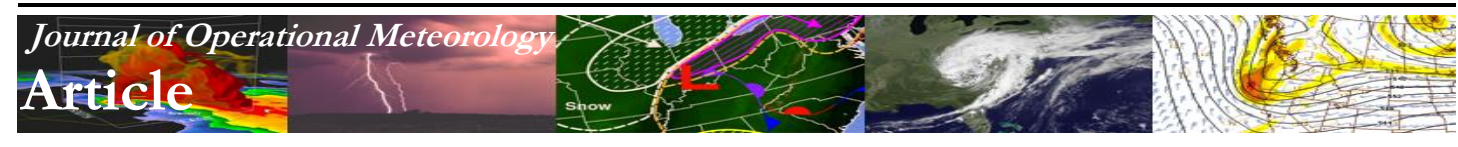

\title{
Utilization of Real-Time Vineyard Observations to Produce Downscaled Temperature Forecasts for Frost Protection Operations
}

\author{
DAVID W. REYNOLDS and TIMOTHY COLEMAN \\ Cooperative Institute for Research in the Environmental Sciences, University of Colorado, Boulder, Colorado
}

DANIEL J. GOTTAS and THOMAS LEFEBVRE

NOAA Earth Systems Research Lab, Boulder, Colorado

(Manuscript received 2 July 2015; review completed 3 December 2015)

\begin{abstract}
Continued drought in California, along with a threatened and endangered salmon population, has required the state of California to control Russian River water usage to protect young, budding winegrape vines during spring frosts. Improved forecasts of the location and duration of frost with increased lead time at individual vineyards could reduce the number of hours of spraying required. In addition, better forecasts could assure adequate supplies of water in off-stream storage systems, reducing demands on tributaries and the threat of fish kills. An automated digital forecast system has been developed and is running routinely to provide vineyard-specific temperature forecasts to growers, commercial frost forecasters, and water managers.

The system is based on the use of a high-resolution terrain grid and focuses on real-time hourly observations from 72 vineyards located within the Russian River Basin. The National Weather Service's (NWS) Graphical Forecast Editor software is configured with a $0.32 \mathrm{~km} \times 0.74 \mathrm{~km}$ grid spacing, and an objective analysis tool is used to generate a high-resolution observation grid of temperature, dewpoint, and relative humidity - along with computed wet-bulb temperature. The minimum values of each of these parameters also are computed. These observed grids are used, in turn, to bias correct the gridded numerical model and model output statistics guidance grids, as well as the NWS official forecast grids, using a 30-day regression of forecast versus observed values. Verification shows that for the overnight lows $\left(\leq 2^{\circ} \mathrm{C}\right)$, the bias correction improves skill in overnight minimum temperature forecasts by a factor of 3-4 for most forecast guidance used.
\end{abstract}

\section{Introduction}

a. The frost problem

The Russian River watershed is located north of San Francisco between two coastal mountain ranges that provide some insulation to the modifying influence of the Pacific Ocean (Fig. 1). The Russian River area is a well-known wine-growing region and is home to 122000 acres of agriculture - a majority of which is vineyards. The Russian River and its tributaries are habitat to three listed endangered salmonid species: Steelhead, Coho, and Chinook salmon. Managing the flows to maintain the salmonid habitat has been a subject of concern for state and federal fisheries resource agencies. As such, the National Oceanic and Atmospheric Administration (NOAA) has selected the Russian River as part of its Habitat Focus Area, with the goal to restore the salmon population by improving their habitat (www.habitat.noaa.gov/habitatblueprint/ russianriver.html). This is specifically related to how the river is managed in terms of flow during critical spawning periods.

During the period from as early as mid-February to mid-May each year, different varieties of winegrape vines begin to bud. During this stage of growth, the buds are highly susceptible to freezing temperatures. Although frost can appear with ambient air temperatures slightly above $0^{\circ} \mathrm{C}$, damaging frost may occur 
with either the ambient air temperature or the wet-bulb temperature $(T w)$ below $0^{\circ} \mathrm{C}$. $T w$ is defined as the temperature a parcel of air would reach if it were lowered adiabatically at constant pressure until the air becomes saturated with respect to water. This is important in that ambient air temperatures can be above freezing but, if the relative humidity is low, spraying water and saturating the air can drop the temperature to below freezing and actually expose the buds to damaging temperatures. Growers can mitigate damage by spraying the plants with water before $T w$ reaches $0^{\circ} \mathrm{C}$ to encapsulate the buds in ice to keep the temperature constant at $0^{\circ} \mathrm{C}$, reducing further exposure to colder temperatures. As an alternative, fans can be used to mix down warmer temperatures from aloft if a shallow, moderately strong temperature inversion exists.

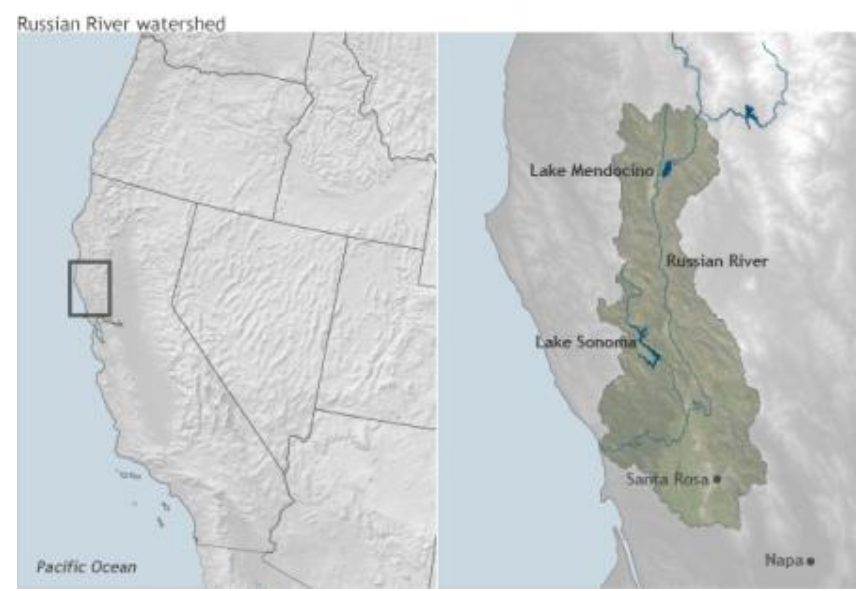

Figure 1. Russian River Basin (right) showing terrain relief. Map on left shows location relative to northern California. Map courtesy of www.climate.gov. Click image for an external version; this applies to all figures hereafter.

During extended dry periods, such as California experienced from 2011 through 2015, water supplies can be scarce, and flows in the river and its tributaries can be very low; thus, any demand (e.g., frost protection) can further reduce flows in the river and larger streams or can dewater smaller tributaries. This can have a significant impact on endangered salmonids developing in the streams, leading to fish strandings and subsequent loss of life. For example, a particularly intense cold spell in the spring of 2008 - which was a dry year in the Russian River Basin-led to a significant fish kill that was thought to have been contributed to by growers trying to protect their crops (www.climate.gov/news-features/features/pairingwine-salmon-climate-lessons-california). Figure 2 in- dicates a drop in flows within the mainstem Russian River during this event.

In the summer months (June through August) water supplies are normally reduced because of the extended dry summers of California's Mediterranean climate. As a result, water used to irrigate the vineyards or to spray on the plants to reduce the heat stress (when temperatures exceed $38^{\circ} \mathrm{C}$ ) also can reduce river flows and/or dewater the smaller streams. The forecast system described here can and is being applied for excessive heat forecasts, but this will not be reviewed in this paper.

The Sonoma County Water Agency (SCWA) is the local jurisdiction responsible for managing the water resources of the Russian River. At their request, NOAA's Earth Systems Research Laboratory (ESRL) Physical Science Division (PSD), in partnership with the local National Weather Service (NWS) Weather Forecast Office (WFO) for the San Francisco Bay Area, began developing a high-resolution, automated, digital, frost forecast system in late 2011. The goal was to provide improved situational awareness with 15-day lead times to growers, SCWA reservoir operators, and water contractors such that water releases from reservoirs might be increased prior to a forecasted frost event. This can decrease the threat of reduced flows by allowing growers with off-stream holding ponds or tanks to fill their supply water if an extended cold spell is forecast. The use of off-steam water supplies, instead of pumping directly from streams, reduces potential drawdowns in the river and minimizes impacts to fisheries. Narrowing the areas forecast to be at risk for frost both spatially and temporally could reduce the hours of unnecessary spraying. Under a new California law restricting water use for frost protection, stream gauges are being installed in many of the tributaries feeding the Russian River. Over the next few years it should be possible to verify that drawdowns are being reduced during frost events and assess the impacts of these frost forecasts on reductions in water usage.

\section{b. Frost and minimum temperature forecast methods and verification}

Snyder and de Melo-Abreu (2005) provided an excellent review of frost forecasting development and current forecast methods, as well as frost mitigation practices. Their recommendations for developing a frost forecast method emphasizes the importance of local observations in developing a statistical regression 


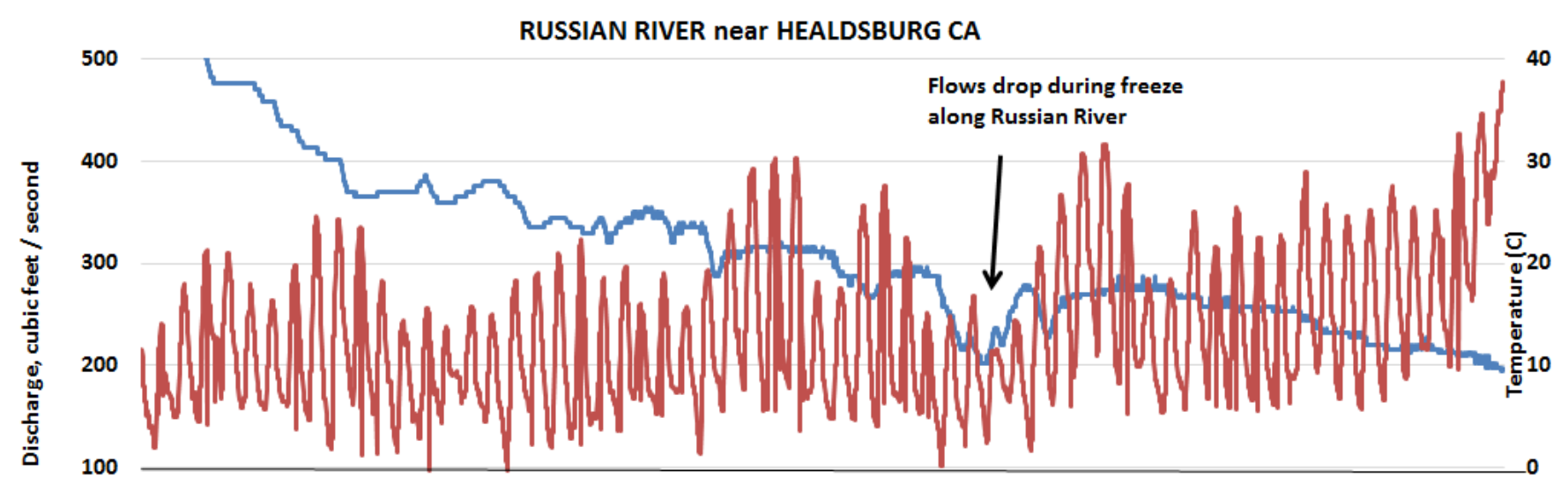

0

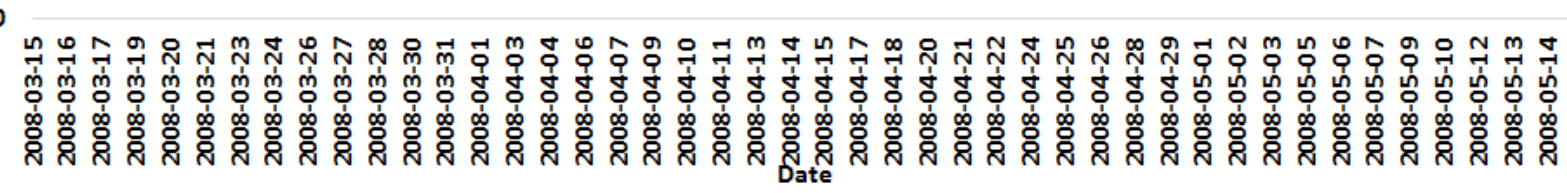

$-10$

Figure 2. Temperature plot $\left({ }^{\circ} \mathrm{C}\right)$ for Healdsburg, CA (red), and the Russian River flows (blue, $\mathrm{ft}^{3} \mathrm{~s}^{-1}$ ) measured near Healdsburg, CA, from 15 March 2008 through 15 May 2008 - the critical period when grape buds are most susceptible to freeze damage. A drop in flows can be seen around 20-24 April 2008, a time when there was a significant salmonid fish stranding.

between the key meteorological parameters and frost occurrence. In this paper we focus specifically on minimum overnight temperatures and minimum overnight $T w$ instead of the occurrence of frost. The growers are aware of the critical thresholds that may cause damage to grape buds, and thus accurate forecasts of these parameters should provide the information to determine whether frost mitigation is necessary.

In addition to straight analytical techniques, simple numerical models have been tested that utilize observations, soil moisture, and radiative parameterization to determine the threat of freezing temperatures. Both Lhomme and Guilioni (2004) and Kala et al. (2009) described the application of simple steady-state energy balance models to predict minimum overnight temperatures. Kala et al. (2009) showed their model forecast probability of detection for a frost event was $55 \%$, and the root mean squared error (RMSE) for nocturnal minimum temperatures was $2.4-3.1^{\circ} \mathrm{C}$.

Katz et al. (1982) described how growers utilize frost forecasts to both assess risk and attempt to reduce costs associated with frost mitigation. In the case described in this paper, the main purpose of the frost forecast is to reduce water consumption because the state has mandated protecting the endangered salmon species. Katz et al. (1982) noted that the real benefit of a frost forecast is to reduce the uncertainty in making the critical decision to mitigate for frost damage. It should be emphasized that the user needs to be provid- ed with both an expected value of the minimum overnight temperatures as well as a measure of uncertainty. As noted by the National Research Council (2006) report, Completing the Forecast, "Uncertainty is thus a fundamental characteristic of weather, seasonal climate, and hydrological prediction, and no forecast is complete without a description of its uncertainty." The appendix will describe output products that help to convey the uncertainty in the forecasts from the forecast system described here.

Development of the software and forecast techniques used in this paper has been an ongoing process within the development of the Graphical Forecast Editor (GFE) software used by the NWS (LeFebvre 1995; LeFebvre et al. 2002). Foisy (2003) and Davis (2004) reviewed the development of the fundamental tools used in GFE for grid editing. These include initializing model guidance grids, creating the "Record of Analysis" (or what is called the observed temperature grids in this paper) to bias correct numerical guidance, and developing "consensus" model forecasts utilizing multi-models and multi-models with postprocessed Model Output Statistics [MOS; Glahn and Lowry (1972)]. Early work by Thompson (1977) described the utility of combining independent forecasts to improve accuracy. Engel and Ebert (2012) demonstrated the advantages of a multi-model consensus forecast with bias correction and model weighting for improved temperature forecasts over Australia. 
Roebber (2010) described another consensus forecast process (called simulated evolution) for next-day minimum temperatures for one city in Ohio. In broad terms, simulated evolution is an iterative process of obtaining the best curve fit between individual forecasts and observations by setting mathematical constraints that, over time, reduce scatter and improve accuracy. Using an independent data sample of 852 days scattered over the four seasons of the year, the system had a mean absolute error (MAE) of approximately $1.65^{\circ} \mathrm{C}$, which was a $27 \%$ improvement over MOS. In the same paper, Roebber also provided an overview of consensus forecasting and its benefits and weaknesses, especially involving rare events. The system to be described here is fully automated, bias corrected, and utilizes a multi-model consensus approach, both in averaging different deterministic model forecasts and in combining statistical post-processed model output. As Mass (2003) noted, an objective bias-corrected technique should do better than subjective manual adjustments of model guidance.

Myrick and Horel (2006) reported on a short, one winter season verification study of the NWS National Digital Forecast Database (NDFD) 5-km surface temperature grids issued at 0000 UTC valid at $12-\mathrm{h}$ intervals through $168 \mathrm{~h}$ (Glahn and Ruth 2003). The forecasts were produced by the NWS Western Region forecast offices and utilized the Mesowest observing network (Horel et al. 2002) at 3000 locations for verification. These forecast offices were utilizing the tools described by Foisy (2003) to produce these forecasts within the GFE software. The results showed forecast errors for temperature grids co-located with Mesowest sites on the order of $3^{\circ} \mathrm{C}$ for lead times $<48 \mathrm{~h}$ and between 3 and $4^{\circ} \mathrm{C}$ from 48 - to 120 -h lead time. The NDFD, now running at $2.5-\mathrm{km}$ grid spacing, is one of the input grids to the current frost forecast system. In section 3 of this paper, verification of the current accuracy of the NDFD temperature forecasts can be compared to those of Myrick and Horel (2006).

\section{c. Current frost forecasts available to growers}

Frost forecasts are provided by two commercial companies in Sonoma and Mendocino Counties (Fig. 3). The Western Weather Group (hereafter referred to as Western $\mathrm{Wx}$ ) provides commercial frost forecasts for Sonoma County (www.westernwx.com/sonoma/ sonomaPM_fcstview.htm), including site-specific minimum temperature forecasts at 12 locations with 15-h lead time and more general guidance (i.e., a range of

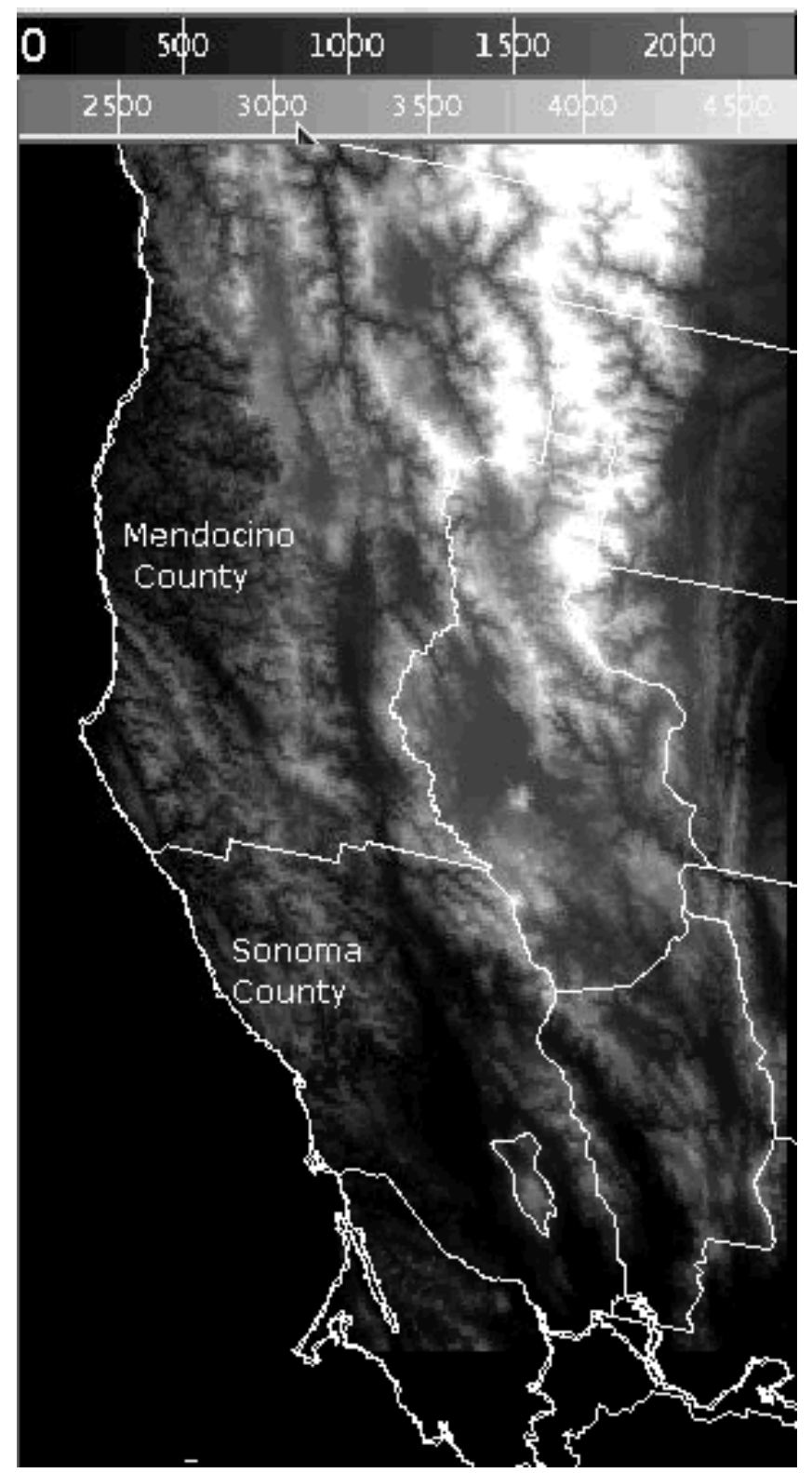

Figure 3. United States Geological Survey 90-m digital elevation grid upscaled to $0.32 \mathrm{~km} \times 0.74 \mathrm{~km}$ as displayed in GFE. The outlines denote county boundaries with the two counties mentioned in the text identified. The key at the top provides the elevation grayscale relationship in $\mathrm{ft}$.

temperatures and frost potential for the entire region) out to 6 days. For Mendocino County, the commercial vendor Fox Weather provides site-specific, high-resolution spatial $(1.5 \mathrm{~km})$ and temporal $(1 \mathrm{~h})$ temperature and humidity forecasts out to 4 days, utilizing a modified version of the Weather Research and Forecast (WRF) model (Skamarock et al. 2008) that assimilates vineyard observations (A. Fox 2014, personal communication). Because availability of the Mendocino County site-specific forecasts is restricted to cli- 
ents, the authors have not had access to either the forecasts or the verification of these forecasts, and thus could not evaluate this system prior to developing the forecast system described in this paper.

Given there are commercial vendors providing site-specific forecasts for vineyard operators, NOAA's role in developing this automated system should be clarified. Under an agreement with the private sector, called the Public Private Partnership (National Research Council 2003), NOAA agreed that the government would not compete with the private sector when a service is currently available or can be provided by the private sector. This agreement does not, however, preclude specific forecasts provided to SCWA, a government agency that has contracted for services with NOAA. NOAA has thus partnered with the commercial vendors and has developed the system described in this paper with full disclosure to the two commercial vendors providing forecasts to Sonoma and Mendocino Counties' winegrape growers. Western Wx has been very open to partnering with and facilitating the dissemination of the NOAA frost forecast products. The Sonoma County Winegrape Commission and Western $\mathrm{Wx}$ have provided links on their web pages to the NOAA forecast products, as will be discussed in the appendix. The Mendocino County commercial vendor, Fox Weather, is aware that these forecasts also cover Mendocino County and has reviewed these products, and thus has access to compare to their gridded forecasts.

The paper is organized as follows. Section 2 discusses the Frost Forecast System (hereafter referred to as FFS) setup and describes the surface observations critical to resolving the microclimates within the Russian River Basin. Section 3 covers verification of the temperature forecasts with a focus on the colder events where frost might occur. However, note that few frost events occurred during the 2014 and 2015 frost seasons, so results shown should be considered preliminary. Finally, section 4 provides general conclusions and recommendations. The appendix briefly reviews the FFS output products.

\section{FFS grid setup and real-time observations}

In developing the requirements for the FFS, it was determined that a high-resolution digital forecast for the entire Russian River Basin was needed that would resolve the detailed microclimates within the basin and that would extend forecasts out to minimally 5 days. The current NWS 2.5-km NDFD gridded forecast was not deemed of sufficient spatial resolution to meet these requirements. It also was determined that a local high-resolution version of the WRF run at $1-\mathrm{km}$ grid spacing at the Monterey NWS WFO would require significant resources and upgrades in boundary layer physics to run twice daily out to 5 days and provide quality gridded forecasts. The most efficient and expeditious approach to meeting the requirements was to adapt the GFE software. Note that the GFE software is available to outside users and is currently being used by government weather agencies in Australia, Taiwan, and Spain. Thus, the tools and techniques to be described below could be adapted and operated for other areas around the globe where forecasts of minimum and maximum temperatures and duration of critical temperatures that negatively impact commerce are needed.

The FFS is currently run from ESRL within the PSD in Boulder, Colorado, and is not currently affiliated with NWS operations. The FFS mimics the operation within an NWS WFO running the GFE software, except there is no manual grid editing. The FFS utilizes the NWS Satellite Broadcast Network (SBN), also known as NOAAPORT, to ingest gridded numerical forecast guidance (Table 1) from the National Centers for Environmental Prediction (NCEP) and MOS bulletins utilizing sites within the Russian River Basin (Table 2). These bulletins are converted to gridded datasets using software developed by NWS forecasters specifically for GFE (Craven et. al. 2013). A majority of the numerical and statistical model data used by FFS can be freely accessed by anyone in real-time via the NOAA Operational Model Archive and Distribution System and converted to the proper file format for use in GFE. Thus, as mentioned earlier, the FFS has applications outside the NWS infrastructure. Although the NDFD could not be used directly to drive the FFS, it is utilized as another numerical forecast guidance product. The NDFD is obtained from the NDFD central server in Silver Spring, Maryland, four times per day $(00,12,18$, and 00 UTC). Two separate WFOs populate the NDFD for the Russian River Basin - the Eureka WFO for Mendocino County and the San Francisco Bay Area WFO for Sonoma County.

\section{a. FFS grid setup}

The GFE software can be set up to run at a userspecified grid spacing. The grid spacing chosen is dependent on computer resources to process and store the myriad of grids generated and the availability of 
Table 1. Forecast guidance available to the FFS.

\begin{tabular}{|c|c|}
\hline Model & Description (Resolution) \\
\hline NAM12/NAMDNG5 & $\begin{array}{l}\text { North American Model }(12 \mathrm{~km}) / \text { downscaled } \\
\text { NAM }(5 \mathrm{~km})\end{array}$ \\
\hline GFS40 & Global Forecast System (40 km) \\
\hline SREF & Short Range Ensemble Forecast (40 km) \\
\hline ECMWF & $\begin{array}{l}\text { High-resolution European Centre for } \\
\text { Medium-Range Weather Forecasts, provided } \\
\text { to NOAA through special agreement with } \\
\text { European Centre }(93 \mathrm{~km})\end{array}$ \\
\hline DGEX & $\begin{array}{l}\text { Downscaled Gridded Experimental-GFS40 } \\
\text { dynamic downscaling using NAM12 (12 } \\
\mathrm{km}) \text {, Days 4-7 only }\end{array}$ \\
\hline HIRESWarw & $\begin{array}{l}\text { High Resolution Western Advanced } \\
\text { Research WRF (arw) model run at } 12 \text { UTC } \\
\text { and } 00 \text { UTC daily }(5 \mathrm{~km})\end{array}$ \\
\hline HIRESWnmm & $\begin{array}{l}\text { High Resolution Western Nonhydrostatic } \\
\text { Mesoscale Model (nmm) WRF model run at } \\
12 \text { UTC and 00 UTC daily }\end{array}$ \\
\hline HPCGuide & $\begin{array}{l}\text { Hydrometeorological Prediction Center } \\
\text { gridded forecast guidance }(5 \mathrm{~km}) \text {, days } 4-7 \\
\text { only }\end{array}$ \\
\hline MOSGuide & Gridded MOS Guidance (5 km ) \\
\hline NDFD & $\begin{array}{l}\text { NWS National Digital Forecast Database (2.5 } \\
\mathrm{km})\end{array}$ \\
\hline ADJMEX & $\begin{array}{l}\text { Adjusted (ADJ) GFS } 40 \text { model using MOS } \\
\text { guidance based on GFS40 through day } 8\end{array}$ \\
\hline ADJMAV & $\begin{array}{l}\text { Adjusted GFS40 model using MOS guidance } \\
\text { based on GFS40 through day } 3\end{array}$ \\
\hline ADJMET & $\begin{array}{l}\text { Adjusted NAM12 model using MOS } \\
\text { guidance based on NAM12 through day } 3\end{array}$ \\
\hline $\operatorname{ADJECS}(E)$ & $\begin{array}{l}\text { Adjusted ECMWF model using MOS based } \\
\text { on ECMWF short term }(S) \text { extended(E) }\end{array}$ \\
\hline
\end{tabular}

Table 2. Cooperative (top 9) and airport MOS sites for the FFS.

\begin{tabular}{|l|l|l|l|}
\hline ID & Latitude & Longitude & Name \\
\hline NSHC1 & 38.2775 & -122.264 & NAPA State Hospital \\
\hline SMAC1 & 38.2994 & -122.462 & Sonoma \\
\hline GRNC1 & 38.4306 & -122.865 & Graton \\
\hline STSC1 & 38.4422 & -122.716 & Santa Rosa \\
\hline STLC1 & 38.5072 & -122.474 & Saint Helena \\
\hline FORC1 & 38.5147 & -123.244 & Fort Ross \\
\hline ANGC1 & 38.5731 & -122.441 & Angwin Pacific Union College \\
\hline CLTC1 & 38.5961 & -122.601 & Calistoga \\
\hline HLDC1 & 38.6175 & -122.873 & Healdsburg \\
\hline STS & 38.5200 & -122.82 & Sonoma County Airport \\
\hline UKI & 39.1400 & -123.23 & Ukiah Airport \\
\hline APC & 38.2130 & -122.28 & Napa Airport \\
\hline
\end{tabular}

high-resolution terrain information. In order to begin to resolve the spatial temperature variability within the Russian River Basin, the 90-m United States Geological Survey Digital Elevation Model terrain data cover- ing the entire basin were obtained. A high-resolution terrain grid has two specific advantages. First, it provides a downscaling method for coarser resolution numerical forecast guidance where vertical temperature lapse rate information allows correction for elevation. Most global and regional forecast models provide low-level vertical temperature and moisture information. This provides a terrain-modified initialization for each of the models that map state parameters to the terrain. Second, the high-resolution spatial terrain grid allows for utilization of a denser surface observation network because individual vineyard observations can be resolved within the grid.

The grid spacing that provided adequate spatial representation covering the entire Russian River Basin and allowed for reasonable computational resources was a $0.38-\mathrm{km}$ west-to-east by $0.74-\mathrm{km}$ north-to-south grid. The terrain grid, as represented in GFE, is shown in Fig. 3. This grid spacing allows adjustment (bias correction using observations) of the coarser-resolution numerical model and statistical forecast guidance (Table 1), which is especially important for models that do not provide low-level vertical thermodynamic information to compute low-level temperature and moisture lapse rates [i.e., SREF and MOSGuide]. The FFS grid has more than 106000 grid points. Simple sampling theory suggests the effective grid resolving area is a little more than $1.1 \mathrm{~km}^{2}$. Given that $80 \%$ of the vineyards are less than $0.40 \mathrm{~km}^{2}$ in Sonoma County (www.sonomawine.com/files/press/SonomaCounty-Wine-Facts-2014.pdf), the FFS would not be able to resolve the temperature over every vineyard, but should be able to resolve the differences in temperatures between vineyards that provide real-time temperature information. Figure 4 a shows a $2 \times 2$ grid sample $(0.76 \mathrm{~km} \times 1.54 \mathrm{~km})$ of the FFS grid on a Google Earth ${ }^{\mathrm{TM}}$ projection positioned near one of the vineyard weather stations. This area represents the effective sampling area corresponding to the vineyard observation. The corresponding FFS grid of daily minimum temperature, valid at 1000 UTC 15 May 2014, is displayed in Fig. 4b. This graphic depicts cooler air located in the Russian River valley bottom to the north and south of the vineyard location, and cooler air located within a tributary to the west compared to the surrounding higher terrain. This figure provides an example of the type of terrain-controlled temperature patterns that can be resolved with the modified GFE terrain and dense surface network. 


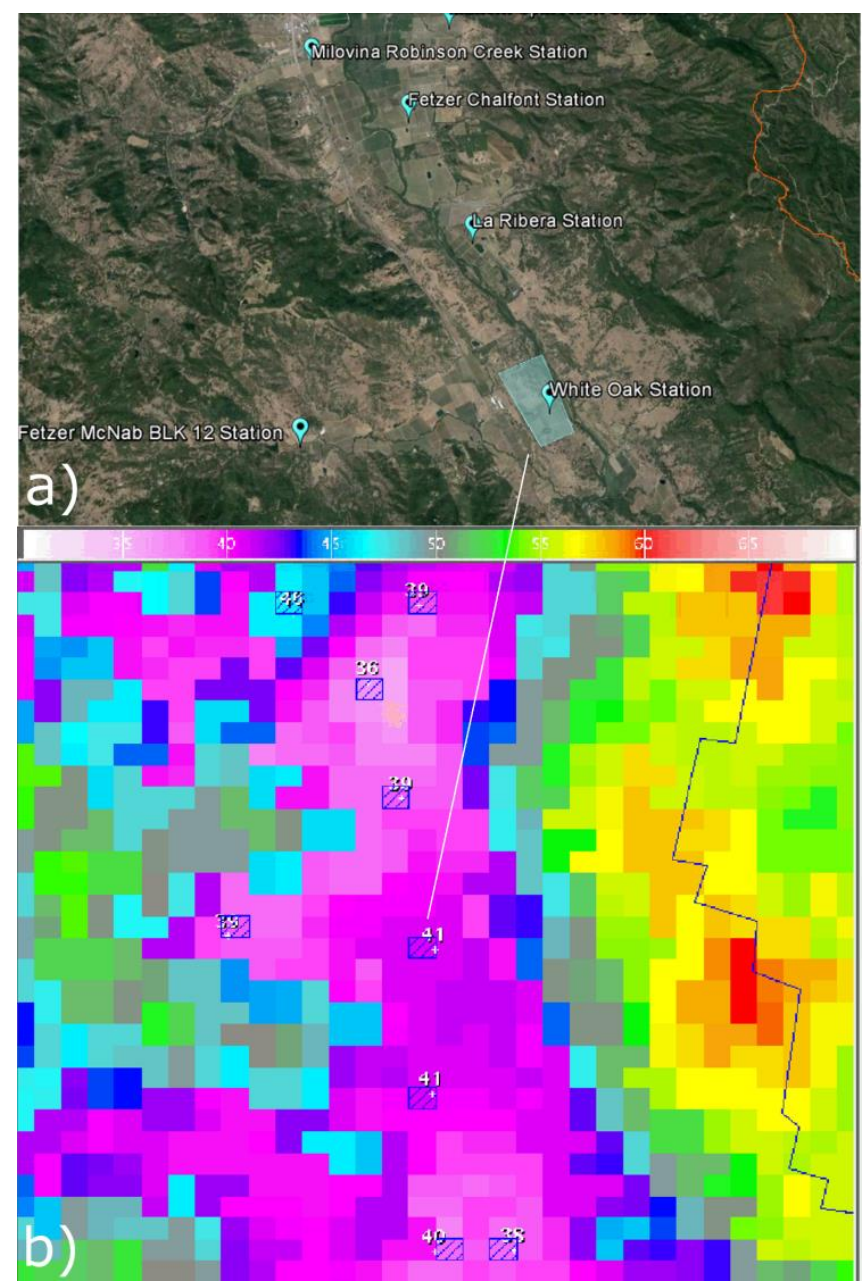

Figure 4. a) Google Earth ${ }^{\mathrm{TM}}$ zoomed in over south-central Mendocino County showing the White Oak Station, which is annotated with a $2 \times 2$ GFE $(0.76 \mathrm{~km} \times 1.54 \mathrm{~km})$ sampling area (cyan-shaded polygon), along with other nearby vineyard sites that provide realtime temperature data. b) FFS MinT observation grid $\left({ }^{\circ} \mathrm{F}\right)$ showing a single grid-cell (hatched area, $0.32 \mathrm{~km} \times 0.74 \mathrm{~km}$ ) that represents the corresponding vineyard observation noted in a). The small white marker located just below the temperature value denotes the location of the vineyard weather station.

\section{b. Real-time observations}

The key to the FFS being able to resolve the microclimates within the Russian River Basin is the use of real-time observations. Real-time or near-real-time (within $3 \mathrm{~h}$ of observing time) surface observations and vineyard observations are obtained via file transfer protocol (i.e., FTP) from the University of Utah's Mesowest data system (Horel et al. 2002), commercial vendors of vineyard weather observing stations (FarmEcology Inc., TeraSpase Inc., and Western Wx), and NOAA's Hydrometeorology Testbed (HMT, hmt.noaa.gov) surface observing networks. A total of 72 real-time vineyard observations have been made

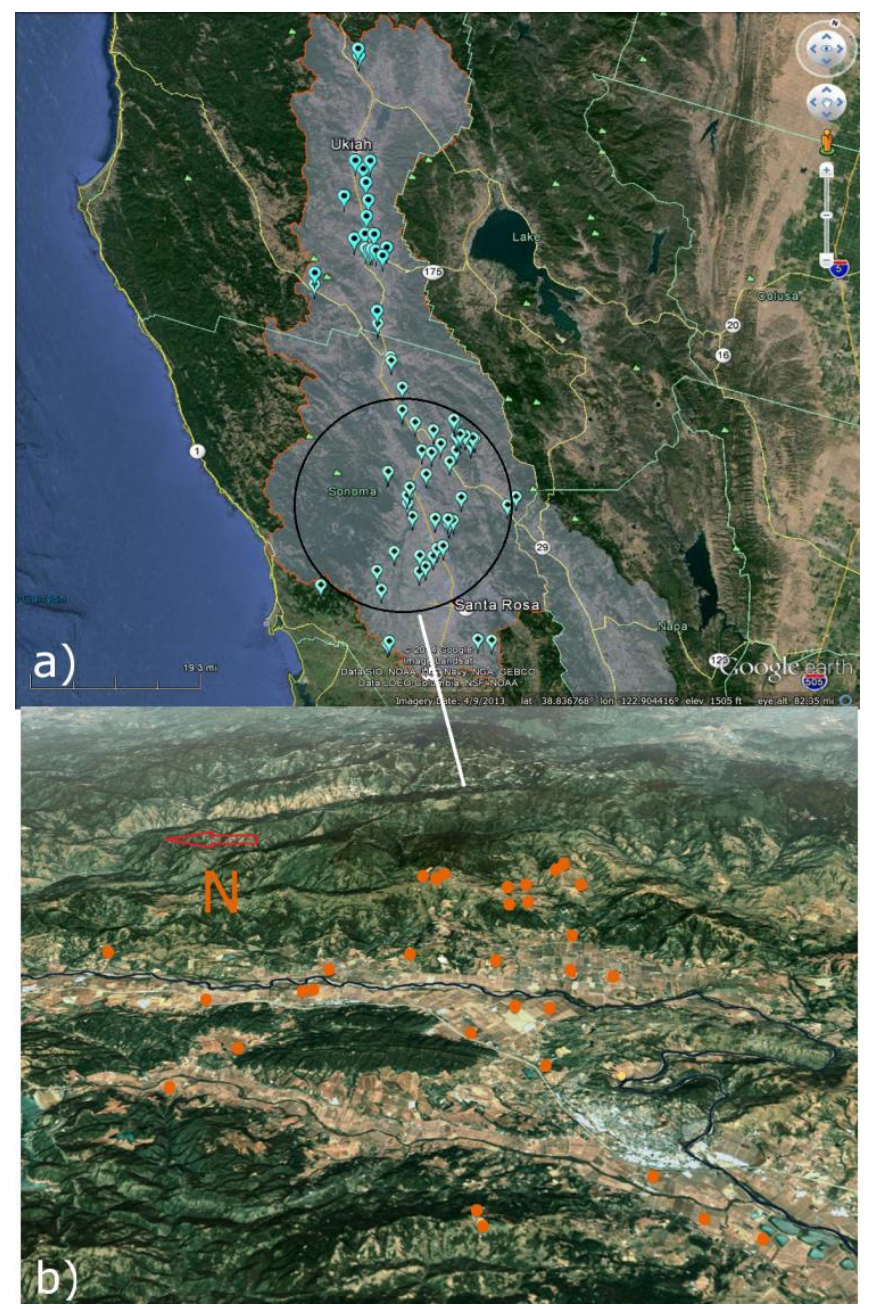

Figure 5. a) Vineyard locations providing hourly data that are used to bias correct the numerical model guidance to account for microclimates due to local terrain. The lightly shaded area outlined in orange is the Russian River Basin. b) Above-horizon perspective of 31 of the 72 sites (orange dots) located in northern Sonoma County shown in cross section looking from the west with vineyards located in the river-bottom, along tributaries, and up on benches above the river valley. Map courtesy of www.climate.gov.

available to the FFS. The real-time vineyard observations utilized for this project are shown in Fig. 5a, with a cross-sectional view of a portion of the observations shown in Fig. $5 b$ to indicate the various elevations of the vineyard observations. NOAA's HMT provides 32 real-time hourly surface observing stations within the domain of the FFS. These consist of 17 conventional surface reporting stations and 15 inversion towers. These towers consist of temperature sensors at 1.5 and $10.5 \mathrm{~m}$. They are used to determine whether a shallow inversion exists such that fans could be used to mitigate frost damage instead of spraying. The $1.5-\mathrm{m}$ temperature on the inversion tower is used in the surface temperature analysis. From Mesowest there are 
approximately 15-20 stations that report hourly within the Russian River Basin. Note that the MOS Cooperative sites (non-airport) listed in Table 2 do not report hourly. Thus, they are not used in the bias correction.

All observations are incorporated into an hourly objectively analyzed observation grid utilizing NCEP's Global Forecast System (GFS40) temperature or dewpoint grid or the previous hour's observed grid as a first guess (Foisy 2003). It was found that the GFS40, downscaled to the high-resolution terrain using vertical temperature lapse rates derived from the model, provided a better first guess than the North American Model (NAM12). This is substantiated by the verification scores provided in section 3 showing the GFS40 outperforming the NAM12 for all temperature forecasts verified at 40 vineyard sites. The gridding process maintains the value of the observation at the closest grid-point location and modifies neighboring grid-point values based on a radius-of-influence that depends on the distance and elevation of the observations. An example of the observed hourly temperature $(T)$ grid is shown in Fig. 6a, along with the NCEP Real-Time Mesoscale Analysis (RTMA; De Pondeca et. al. 2011) hourly 5-km grid in Fig. 6b for comparison. The RTMA grid shown is identical to that which is available to NWS forecast offices. It is obvious how much more detail is derived by having the vineyard and inversion tower observations in addition to the routine surface observations from Mesowest and HMT, along with utilizing the higher-resolution terrain data. The hourly observed temperature and dewpoint grids are used to generate daily minimum observed temperature (MinT), daily observed maximum temperature (MaxT), daily observed minimum relative humidity (MinRh), and daily observed maximum relative humidity (MaxRh) grids. Because sub-hourly temperatures are not available, the actual minimum and maximum values are not exact. For 12 of the 72 stations (those data that are published by Western $\mathrm{Wx}$ for Sonoma County), the actual minimum and maximum temperatures were observed and are available for comparison. These values can vary by up to $0.5^{\circ} \mathrm{C}$ cooler for MinT and $0.5^{\circ} \mathrm{C}$ warmer for MaxT than what the GFE hourly values would indicate.

An adjustment (bias correction) to the model forecast $T$, dewpoint temperature $(T d)$, and derived $\mathrm{Rh}$ grids (NDFD and models) is applied by using a 30-day linear regression between the model forecast $T$ and $T d$ grids and the corresponding hourly observation grids. A bias correction is computed at each grid point of the forecast guidance. The computed MinT, MaxT, MinRh, and MaxRh from the observed hourly grids are used again to bias correct the model and MOS forecast MinT, MaxT, MinRh, and MaxRh grids at every grid point. Hourly observed $T$ and $T d$ grids are used to calculate an observed $T w$ grid assuming a United States standard surface pressure, and from these a MinTw grid is calculated. The bias-correction method has proven to be highly reliable in generating modified grids and has been used for more than a decade in at least the NWS Western Region WFOs. Although this is referred to as bias correction (BC), as Glahn (2012) states this is not an accurate description because the differences between model forecast and observed temperatures are more related to model forecast errors and not to a systematic cold or warm bias seen over much longer periods. However, by using these grid-by-grid differences in model forecasts versus observations, the adjustment to the original model grids will better resolve small-scale differences where real-time observations are available. It sets out to accomplish what Mass et al. (2008) described for bias correcting the MM5 model run at the University of Washington. The Washington researchers first estimate bias at observing locations using errors from forecasts that are similar to the current forecast. These observed biases are then used to estimate bias on the model grid by pairing model grid points with stations that have similar elevation and/or land-use characteristics. The bias-correction method used in the FFS does at times degrade the forecast when there is a significant airmass change and the most recent 30-day difference in model versus observed forecasts may not be appropriate, as Mass et al. pointed out with their method. A second method called Analog was developed to provide an alternative forecast when an event such as this occurs. It will be described later in this section.

Figure 7a shows the original ensemble mean MinT grid for the SREF provided over the SBN at $40-\mathrm{km}$ grid spacing. It was noted earlier that the SREF was one of the models that had no vertical temperature or moisture information to allow for initializing to the terrain. Thus, the bias-correction method is the only way to adjust this model for terrain influences. Figure $7 \mathrm{~b}$ shows the adjusted MinT grid after applying the bias correction. Note how the terrain features stand out as well as where coastal marine influences penetrate inland. The same process is done for MaxT, MinRh, and MaxRh. For MOS guidance, where only MinT and MaxRh are provided, the regression-adjusted MinT 


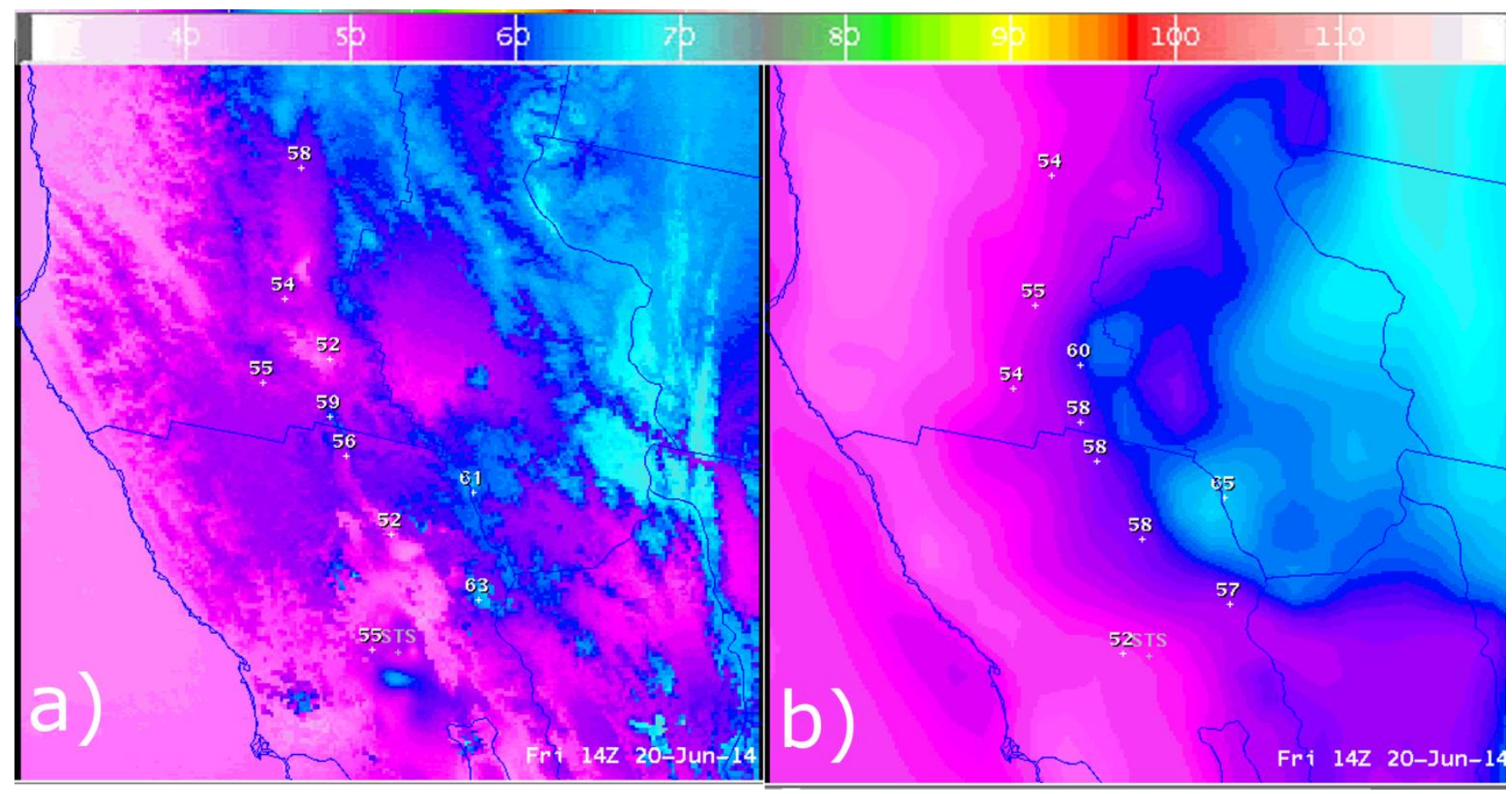

Figure 6. Surface temperature analysis valid 1400 UTC 20 June 2014. a) Objective surface analysis from FFS using all real-time stations. b) RTMA. Sample points in a) are observed temperature values $\left({ }^{\circ} \mathrm{F}\right)$ at the locations of a select set of vineyard real-time observing sites and in b) are values derived from the RTMA grid $\left({ }^{\circ} \mathrm{F}\right)$.

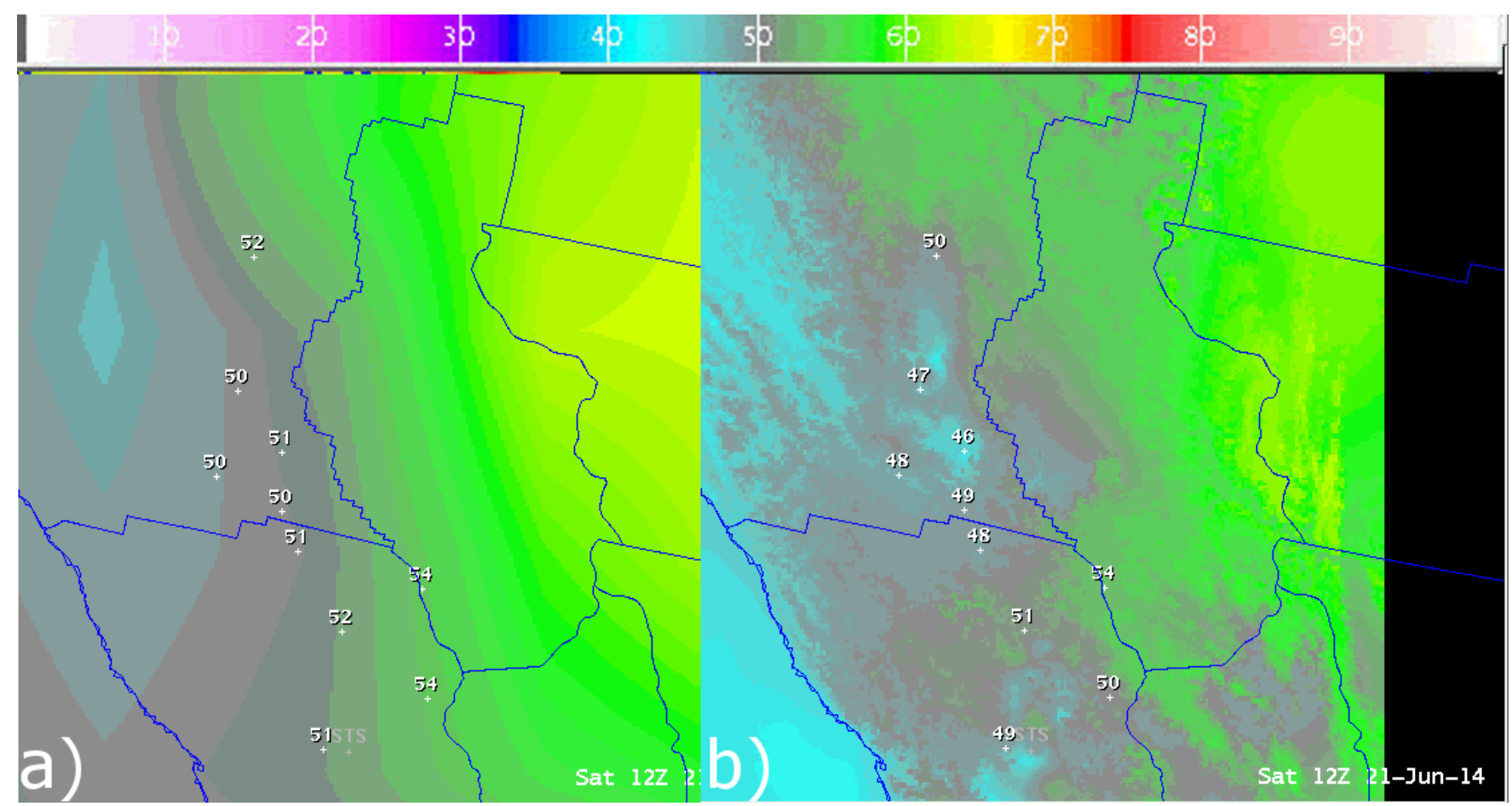

Figure 7. a) Raw SREF 40-km grid of ensemble mean MinT grid $\left({ }^{\circ} \mathrm{F}\right)$ showing a coarse west-to-east temperature gradient. b) Same grid as a) but adjusted using the 30-day regression between the forecast and observed MinT.

(MinTBC) and MaxRh (MaxRhBC) can be used to calculate MinTw assuming a United States standard surface pressure. For numerical forecast guidance where 3-h or 6-h temperature and dewpoint grids are available, $T w$ can be directly calculated and a minimum $T w$ derived. These can be bias corrected 
using the observed $T w$ grids. According to Snyder and de Melo-Abreu (2005), $T w$ is the most critical parameter for determining when to begin to operate sprinklers for frost protection. Their recommendation is to begin sprinkling before $T w$ is $\leq 0^{\circ} \mathrm{C}$.

As noted, the key to downscaling the forecasts to individual vineyards is heavily dependent on receiving quality observations in near real-time; thus, it is very important to quality control the observations before they are used in the bias-correction scheme. Obvious observed temperature or humidity outliers are removed via a simple software algorithm that monitors for temperatures exceeding the specified criteria $\left(>60^{\circ} \mathrm{C}\right.$ or $\leq-20^{\circ} \mathrm{C}$ ) or $\mathrm{Rh}$ values $(>100 \%$ and $<0 \%)$. Thus, the FFS still needs manual intervention to remove subtler instrument errors. About a month before and during the frost season, the observation grids are manually viewed once daily using the GFE graphical user interface to determine if erroneous data are being received from any of the observing stations used by the FFS. A station noted as reporting an erroneous temperature or dewpoint has its name placed in a file that flags that station's erroneous sensor so it is not used in the surface observing grid. During the frost season, the observations are monitored daily to see if the station reporting a bad sensor has been corrected. Once the sensor is corrected, its name is removed manually from the file. For any given hour, from 50 to 60 quality-controlled vineyard observations are available. Because NOAA is reliant on the commercial vendors for receipt of the vineyard observations, it has no control over station reporting reliability or sensor maintenance. NOAA does, however, report erroneous data to the commercial vendors. On any given day, between 15 and 25 stations out of the possible 120 stations available to the FFS have one or more sensors reporting erroneous data.

\section{c. Additional FFS forecast guidance tools}

Over the past several years NWS forecasters have developed other methodologies, in addition to the biascorrection technique, to improve temperature forecasts using the GFE software. A technique called Analog, developed by Colin (2006), allows the forecaster to select a model or the average of several models' current forecasts and the number of days of past forecasts to compare to. The algorithm then identifies the 5 days that correlate best to the current forecast of the specific parameter chosen. For the case of the FFS, MinT, MaxT, and MinTw are the parameters run through the
Analog algorithm. The algorithm then adjusts the current forecast (from the selected model or models chosen) based on the mean of the forecast errors for the five best matching days for each grid point. For the FFS, the average of the GFS40 and GFS40BC are used as the current forecast. Other model choices can be used, but from internal testing and verification during prototype development, it was found the GFS40 and GFS40BC provided consistently higher skill scores. This may need to be reevaluated based on verification of the Analog technique reported in section 3. The last 20 days of forecasts of both models are used as the sample for finding the five best matches. The selection of 20 days was somewhat arbitrary and could be run using a longer period to capture more extreme events. Future work will experiment with varying the number of days to determine the impact on skill and computer resources. The technique is only run for forecasting days 1 and 2. Again, this method was applied as an alternative to the bias-correction method to overcome its limitations when there was a significant airmass change that may render the 30-day regression unsuitable.

An additional set of consensus forecast grids (CONS), developed by the NWS Central Region (Craven et al. 2013), combines the raw models, raw MOS, adjusted (BC) models, and adjusted (BC) MOS - as well as the NDFDBC grids - to form an ensemble forecast. The various CONS ensemble configurations are shown in Table 3. The CONS system uses a simple mathematical average of corresponding grid points for the models as shown in the columns in Table 3. [Refer to Table 1 for a definition of the model names and description.] The technique has shown merit and has been incorporated into the FFS. Its utility will be shown in the next section on verification.

\section{Forecast verification}

The NWS GFE software has a verification software package called Boise Verify (Jenks et al. 2012) that compares forecast grids to the objective analyses of surface observations as described earlier. Verification scores have been calculated for MinT, MaxT (results not discussed), MinTw, and hourly $T$ and $T w$ (results not discussed) for a sample of forecast grid boxes at 40 of the 72 vineyard sites in both Sonoma and Mendocino Counties. These 40 sites (Fig. 8) represent a diverse cross section of valley and bench (elevated vineyard sites) locations and should be 
Table 3. Numerical models used to create the NWS CONS guidance grids.

\begin{tabular}{|c|c|c|c|c|c|c|c|c|c|}
\hline & CONSAll & CONSRaw & CONSMOS & BCCONSAII & BCCONSRaw & BCCONSMOS & AllBlend & BCAllBlend & WModel \\
\hline GFS40 & $\mathbf{x}$ & $\mathbf{x}$ & & & & & \multirow{11}{*}{$\begin{array}{l}50 \% \text { of } \\
\text { all these } \\
\text { models }\end{array}$} & & \multirow{22}{*}{$\begin{array}{l}\text { Blend of } \\
\text { the top } 3 \\
\text { models } \\
\text { over the } \\
\text { last } 7 \text { days }\end{array}$} \\
\hline ECMWF & $\mathbf{x}$ & $\mathbf{x}$ & & & & & & & \\
\hline DGEX & $\mathbf{x}$ & $\mathbf{x}$ & & & & & & & \\
\hline $\begin{array}{l}\text { NAM12 } \\
\text { NAMDNG5 }\end{array}$ & $\begin{array}{l}\mathbf{X} \\
\mathbf{X}\end{array}$ & $\begin{array}{l}\mathbf{X} \\
\mathbf{X} \\
\end{array}$ & & & & & & & \\
\hline SREF & $\mathbf{x}$ & $\mathbf{x}$ & & & & & & & \\
\hline ADJMEX & $\mathbf{x}$ & & $\mathbf{X}$ & & & & & & \\
\hline ADJMAV & $\mathbf{x}$ & & $\mathbf{x}$ & & & & & & \\
\hline ADJMET & $\mathbf{x}$ & & $\mathbf{x}$ & & & & & & \\
\hline $\begin{array}{l}\text { ADJECS } \\
\text { ADJECE } \\
\end{array}$ & $\begin{array}{l}\mathbf{X} \\
\mathbf{X} \\
\end{array}$ & & $\begin{array}{l}\mathbf{X} \\
\mathbf{X} \\
\end{array}$ & & & & & & \\
\hline MOSGuide & $\mathbf{x}$ & & $\mathbf{x}$ & & & & & & \\
\hline HPCGuide & $\mathbf{x}$ & & $\mathbf{x}$ & & & & & & \\
\hline GFS40BC & & & & $\mathbf{x}$ & $\mathbf{x}$ & & & \multirow{10}{*}{$\begin{array}{l}50 \% \text { of all } \\
\text { these models }\end{array}$} & \\
\hline ЕСМWFВС & & & & $\mathbf{x}$ & $\mathbf{x}$ & & & & \\
\hline DGEXBC & & & & $\mathbf{x}$ & $\mathbf{x}$ & & & & \\
\hline NamDNG5BC & & & & $\mathbf{x}$ & $\mathbf{x}$ & & & & \\
\hline SREFBC & & & & $\mathbf{x}$ & $\mathbf{x}$ & & & & \\
\hline ADJMEXBC & & & & $\mathbf{x}$ & & $\mathbf{x}$ & & & \\
\hline ADJMAVBC & & & & $\mathbf{x}$ & & $\mathbf{x}$ & & & \\
\hline ADJMETBC & & & & $\mathbf{X}$ & & $\mathbf{X}$ & & & \\
\hline $\begin{array}{l}\text { ADJECSBC } \\
\text { ADJECEBC }\end{array}$ & & & & $\begin{array}{l}\mathbf{X} \\
\mathbf{X} \\
\end{array}$ & & $\begin{array}{l}\mathbf{X} \\
\mathbf{X} \\
\end{array}$ & & & \\
\hline MOSGuideBC & & & & $\mathbf{x}$ & & $\mathbf{x}$ & & & \\
\hline NDFDBC & & & & & & & $\mathbf{5 0 \%}$ & $50 \%$ & \\
\hline
\end{tabular}

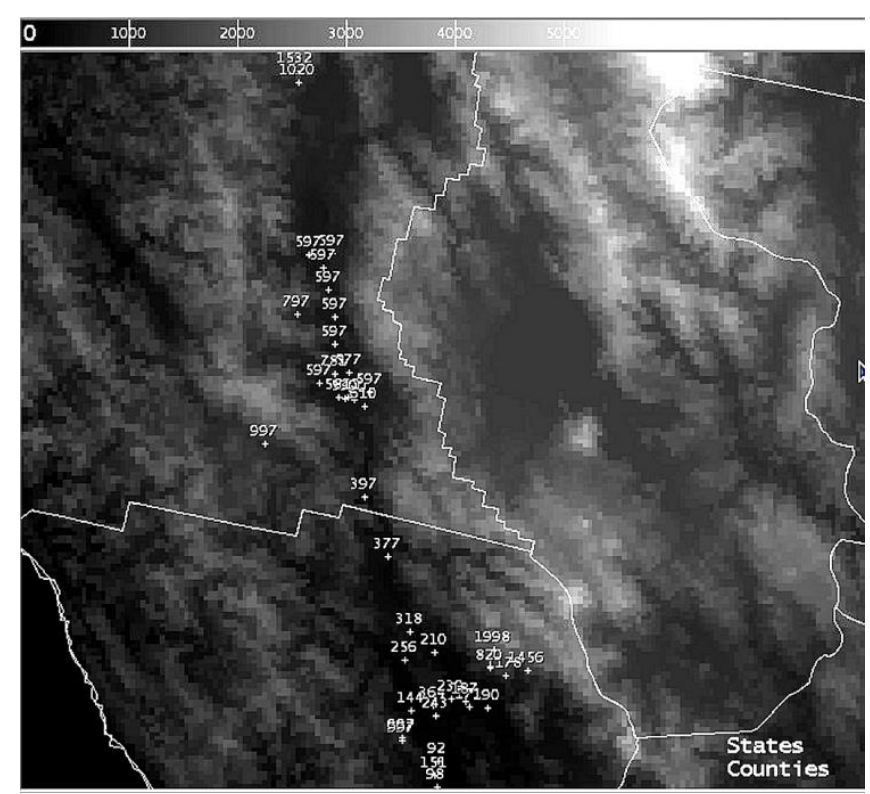

Figure 8. Terrain image with the 40 vineyard sample points annotated with site elevation shown in $\mathrm{ft}$. representative of the performance of the system. They also represent the most reliable stations in terms of real-time reporting performance. It is important to make sure verification is performed for observed temperatures and not at locations where observations may have been missing for many days during the verification period. As noted earlier, NOAA had no control over the availability of each vineyard weather station's data. Because the surface objective analyses scheme maintains the value of the observation where available, it is possible to use the Boise Verify code, which is designed to do gridded verification, to perform stationby-station verification. For verification purposes, the actual grid box that encompasses the surface observation (refer back to Fig. 4) is compared with the same forecast grid box.

There are various ways of evaluating the accuracy of a forecast. Conventional methods include the MAE or RMSE as a function of forecast lead time. MAE is used for this study. However, the results to be shown 
would not have changed significantly had RMSE been used. Although this paper is focused on frost events, it is useful to evaluate the FFS for daily MinT during the frost season as this constitutes a much larger data sample than just frost dates. Also, it will provide a point of comparison with previous studies referred to in section 1 that have noted the accuracy of forecasting overnight low temperatures. The forecast value of
MinT at each forecast lead time is compared to the observed MinT at that grid point, and the MAE is computed for each model available. The results of this are shown in Fig. 9 for the 40 sites for the periods 15 March 2014-15 May 2014 and 20 February 2015-15 May 2015-the peak frost season for the Russian River Basin for these two years. Budding started early in 2015 , so the season was initiated earlier.

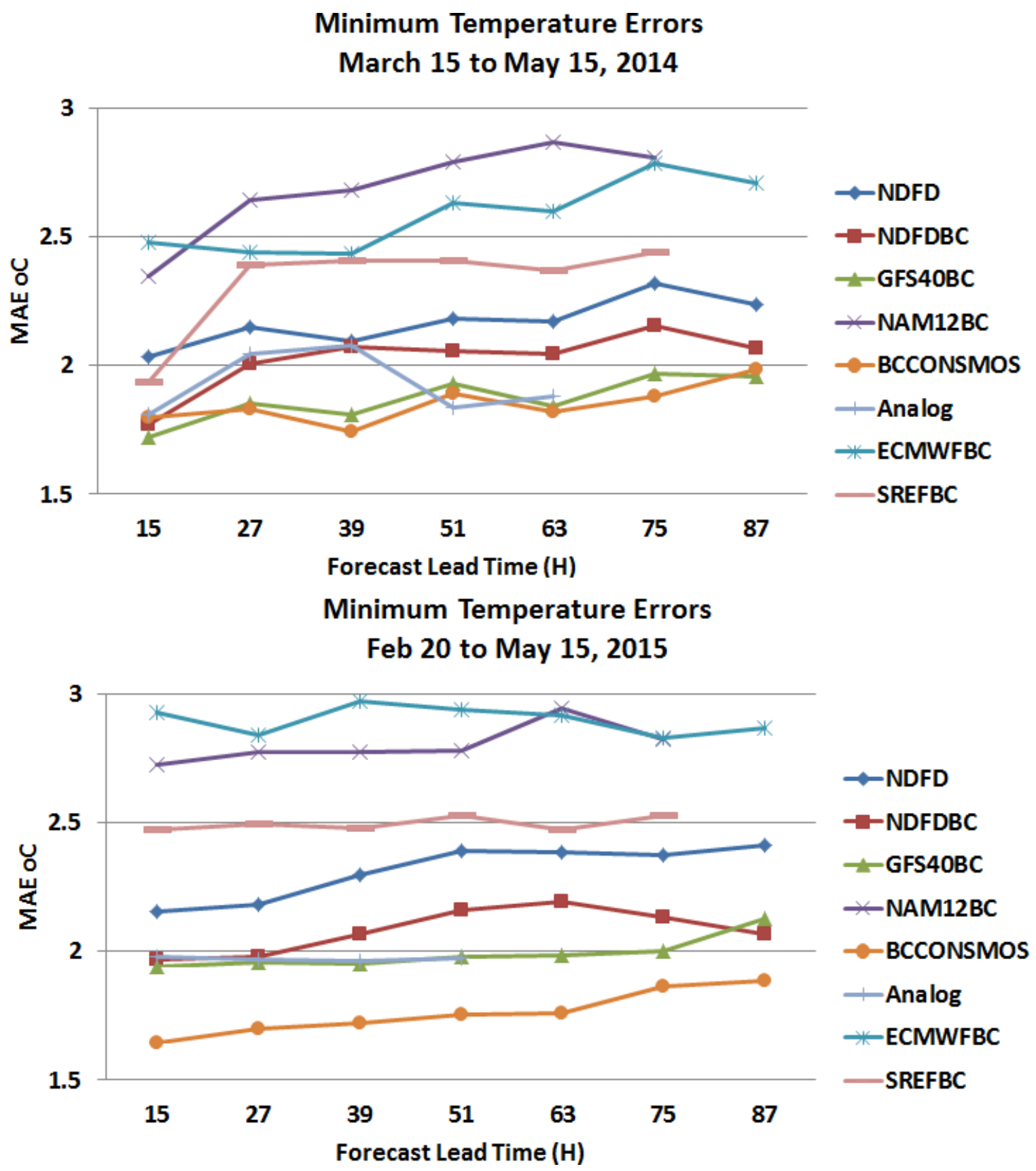

Figure 9. Mean absolute errors (MAE) with respect to forecast lead time for two frost seasons (2014 and 2015). Refer to Table 1 for model names. These forecasts include only the 12 UTC and 00 UTC model cycles to assure that there are common samples among the various forecasts. The Analog plot for 2015 falls almost directly atop the GFS40BC plot. 
Results shown (Fig. 9) are a subset of all the possible model forecasts available from the 12 and 00 UTC model runs. Included are all of the bias-corrected numerical forecast model guidance (09 UTC and 21 UTC with SREFBC lead times shifted $3 \mathrm{~h}$ forward to match other models) along with the NDFD and biascorrected NDFD(BC), the Analog technique, and the consensus bias-corrected MOS guidance (BCCONSMOS). The magnitude of the MinT forecast errors can be compared to the previous MinT forecast studies noted in section 1 . These previous studies showed errors of 1.5 to 3 or $4^{\circ} \mathrm{C}$ for overnight minimums with lead times of $15 \mathrm{~h}$ to more than 3 days. The FFS results for the best-performing guidance are very comparable to, or even more accurate than, these earlier studies (Myrick and Horel 2006). The year-to-year ranking of the selected models and statistical guidance is very consistent between the two years. The BCCONSMOS is consistently near or is the best model at each forecast lead time. In fact, its day 3.5 forecast in 2015 is better than any other model's 15 -h forecast. This emphasizes the benefit of the CONS method and use of MOS guidance. Also note the much higher accuracy of the GFS40BC model guidance versus the other most used numerical model guidance, the NAM12BC and ECMWFBC. These are significant differences and further studies are needed to determine the reason for these large differences. Another important result is that one can identify the improvement in using the bias-correction method by comparing, for example, the raw NDFD forecast and the bias-corrected NDFD(BC) forecast. Although the absolute difference in MAE is rather small, the NDFDBC provides 1-2 days of lead time improvement over the NDFD in both years. In comparing the other models' bias versus non-bias-corrected MAEs for MinT, in almost all cases the BC version's day 3 forecast is better than the 15-h non-bias-corrected forecast. This comparison indicates the benefit of using both the higher resolution terrain grid and access to the real-time vineyard observations. The MinTw scores also were compared for the two years with the model rankings very similar to MinT. MAE values were a few tenths of a degree lower (more accurate) than MinT values for all models for 2014 and a few tenths higher than MinT for all models for 2015 (less accurate).

The following verification results will focus on the coldest events observed during the frost seasons, as these are the most critical to the growers and water managers. To place this in perspective, during frost seasons 2012, 2013, 2014, and 2015, few freeze events occurred during the winegrape budding season, which climatologically runs from 15 March to 15 May each season. Table 4 shows the average number of days of freezing to sub-freezing temperatures for two Russian River valley climate stations [Ukiah (Mendocino County) and Healdsburg (Sonoma County)] and the number of freezing to sub-freezing overnight minimums observed the last four years for the 4-mo period from February to May. The results show 2014 and 2015 were well below average in number of days below freezing. The 2014 frost season had only three stations of the 40 used in the verification reporting morning minimum temperatures below $0^{\circ} \mathrm{C}$. This was only $0.1 \%$ of the possible 2480 morning lows during the 62 days of the frost season (62 days times 40 stations). Figure 10 shows the long-term trends in lowest monthly MinTs for the same two climate stations. Plotted are the 10-yr running means along with the 10-yr mean in the Pacific Decadal Oscillation, a possible climate driver for the oscillations in extreme MinT seen in the plot (Gershunov et al. 1999). Although there are short-term up and down trends in extreme MinT, the overall trend is for warming of extreme MinTs since the early 20th century at both locations. Although this is a very good trend for growers and water managers, it makes it somewhat more challenging to forecast damaging frost, which is becoming a rare event. In fact, what may be occurring is the frost season is starting earlier, such as into midto-late February and is virtually over by early May (personnel discussion with growers). This was the case for the 2015 frost season. Growers reported certain varietals of grapes began to bud in February. Thus, the frost season for 2015 was expanded to include the period from 20 February to 15 May, which was why February was included in Table 4 . There were again but a few observed morning minimum temperatures below freezing during 2015, with just under $4 \%$ of the possible morning minimums reporting sub-freezing temperatures for the 40 stations during the almost 3mo period.

Given the small sample size of freezing temperatures, the threshold used to identify potential frost days was $2^{\circ} \mathrm{C}$. This has some precedence as Kala et al. (2009) used $2^{\circ} \mathrm{C}$ for temperatures in Australia as a possible indicator of frost occurrence. This population constituted $3 \%$ of the observed morning minimum temperatures for 2014 and $15 \%$ of the population for 2015. The increase was driven by expanding the frost season into the last two weeks in February and first two weeks in March when a majority of the colder 
Table 4. Climatology of $\leq 0^{\circ} \mathrm{C}$ overnight minimums at two stations in the Russian River Valley and observed freezing/sub-freezing temperatures during the 4-mo period of possible frost season for past 4 yr. February was included as the frost season initiated in February 2015.

\begin{tabular}{|l|c|c|c|c|c|}
\hline Ukiah 1900-2012 & Average \# of Days $\leq \mathbf{0}^{\mathbf{0}} \mathbf{C}$ & $\mathbf{2 0 1 2}$ & $\mathbf{2 0 1 3}$ & $\mathbf{2 0 1 4}$ & $\mathbf{2 0 1 5}$ \\
\hline February & 7.5 & 5 & 11 & 4 & 0 \\
\hline March & 4.5 & 2 & 3 & 0 & 0 \\
\hline April & 1.6 & 2 & 1 & 0 & 0 \\
\hline May & 0.2 & 0 & 1 & & 0 \\
\hline Healdsburg 1893-2012 & & & & & \\
\hline February & 3.4 & 4 & 10 & 4 & 0 \\
\hline March & 1.6 & 1 & 0 & 0 & 0 \\
\hline April & 0.4 & 0 & 0 & 0 & 0 \\
\hline May & 0 & 0 & 0 & 0 & 0 \\
\hline
\end{tabular}

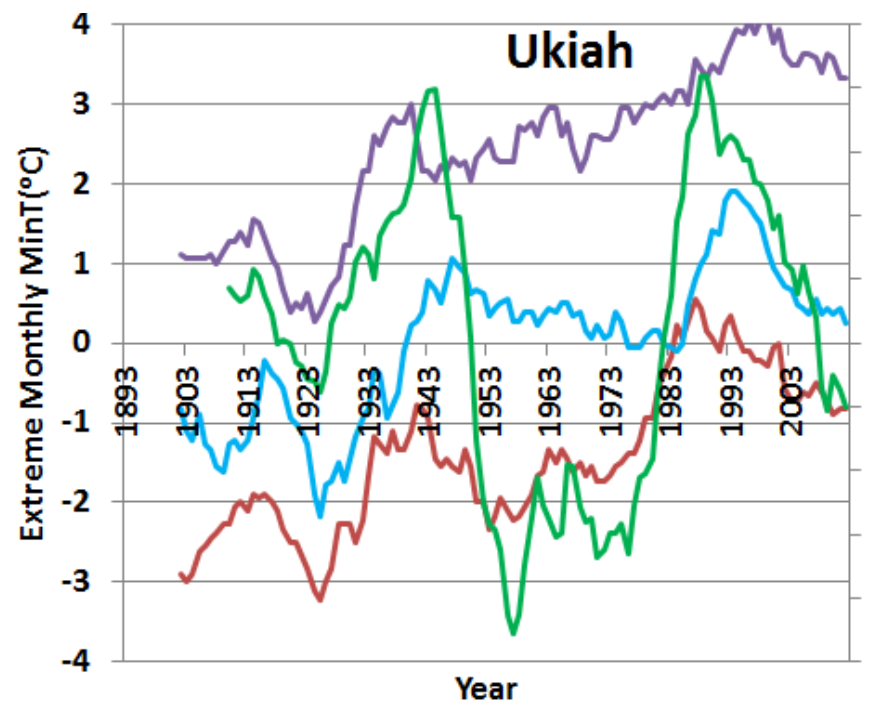

1

0.8

0.6

0.4

$0.2-M a r 10 \mathrm{Yr}$

$0 \mathrm{O} \longrightarrow$ Apr $10 \mathrm{YR}$

$-0.2-$ May $10 \mathrm{yr}$

$-0.4 \longrightarrow$ PDO $10 \mathrm{Yr}$

$-0.6$

$-0.8$

$-1$

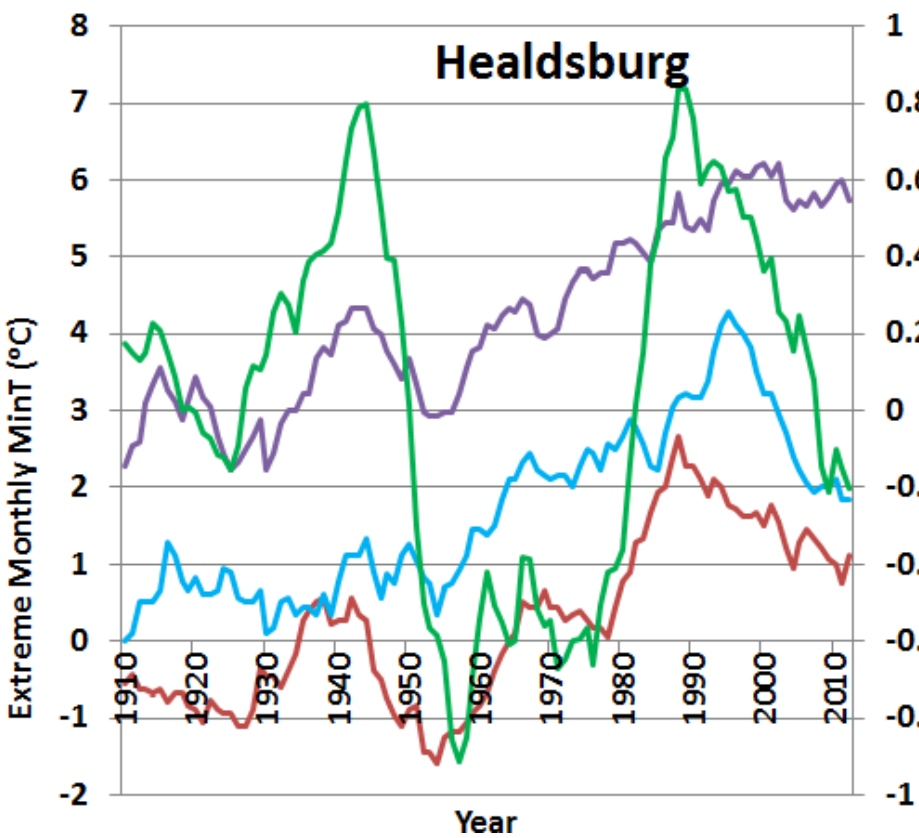

Figure 10. 10-yr running averages of extreme monthly MinT $\left({ }^{\circ} \mathrm{C}\right)$ for Ukiah and Healdsburg over the past $100 \mathrm{yr}$ or more along with the 10-yr running mean of the Pacific Decadal Oscillation (green line) that may have some relation-ship to the decadal variations in observed MinTs ( $\mathrm{r} \cong 0.5$ for 10-yr PDO and March 10-yr extreme monthly MinT for both stations). 
temperatures were observed. Given the much larger sample size for 2015, the 2015 frost season will be used to evaluate the FFS performance in forecasting the coldest mornings. Because this is just one season, the results should be considered preliminary and suggestive of the future performance of the FFS.

Figure 11 shows the Equitable Threat Score (ETS), also referred to as the Gilbert Skill Score, for minimum temperatures $\leq 2^{\circ} \mathrm{C}$ for the 2015 frost season for models run at $12 \mathrm{UTC}$ and $00 \mathrm{UTC}$. The ETS is described in Mason (2003) and accounts for the correct forecasts that can simply occur by chance $\left(a_{\text {random }}\right)$. An ETS of zero means the forecast was no better than chance, whereas an ETS of 1 is a perfect forecast. The ETS is defined as:

$$
\text { ETS }=\left(a-a_{\text {random }}\right) /\left(a-a_{\text {random }}+b+c\right),
$$

and

$$
a_{\text {random }}=(a+b)(a+c) /(a+b+c+d)
$$

where $a$ is the number of correct forecasts at or below the frost threshold, $b$ represents the number of false alarms of frost, $c$ is the number of incorrect forecasts or missed frost events, and $d$ is the number of correct forecasts of frost not occurring.

The models displayed are limited by needing to have matching days and lead times. This limited the forecast lead time given that the Analog model only goes out to $51 \mathrm{~h}$. Figure 11 includes all the bias-corrected numerical guidance, the gridded bias-corrected MOS product (MOSGuideBC), and a majority of the CONS bias-corrected numerical and statistical ensembles. For comparison, two non-bias-corrected models are shown - the NDFD and the CONSMOS. One can compare the ETS for the bias-corrected and non-biascorrected values noting that the bias correction in both cases greatly improves the forecast skill by a factor of 3 or 4 . This degree of improvement was found with almost all the non-bias-corrected models compared to their bias-corrected version. The GFS40BC is the best numerical guidance similar to what was shown in Fig. 9, with MOSGuideBC the best statistical model. The BCCONSMOS was still one of the top performers. The Analog technique showed skillful forecasts out at day 1.5 and day 2, but still not as skillful as the GFS40BC. Because the Analog technique utilizes the GFS40BC as one of two models it averages (GFS40 being the other), it appears that the technique of finding the 5 best matches versus simply bias correcting the GFS40 using the past 30 days of regression is not adding more skill. Note the GFS40BC shows a more skillful forecast at $51 \mathrm{~h}$ than the NDFDBC at 15-h lead time. Again, one sees the NAM12BC and ECMWFBC with much lower skill in forecasting the coldest morning lows. It can only be assumed that the 30-day regression of observed to forecast MinT has a large scatter for both models, and thus the tail of the distribution is poorly estimated.

Verification also was performed for the minimum daily $T w$ (MinTw) as $T w$ is the critical forecast parameter to be monitored for water spray mitigation as referenced earlier from Snyder and de Melo-Abreu (2005). Figure 12 shows the ETS as a function of forecast lead time for MinTw using the $2^{\circ} \mathrm{C}$ threshold as in Fig. 11 for the 40 sites during the 2015 frost season. Although the magnitudes of the ETSs are slightly lower, the relative ranking of the guidance is very similar to MinT. The lower ETSs are most likely a reflection of the guidance's ability to forecast the low-level relative humidity, which has a large influence on MinTw.

It is useful to compare the FFS skill to that of the commercial vendor Western $\mathrm{Wx}$ who publishes its frost forecasts for Sonoma County. Western Wx provides a site-specific, 15-h forecast of MinT for 12 sites listed in Table 6 . This forecast is provided as the most likely forecast (i.e., highest probability) given expected winds and cloud cover (see www.westernwx.com/ sonoma/sonomaPM_fcstview.htm for details). The ETS was calculated using the same $2^{\circ} \mathrm{C}$ threshold as was used for Fig. 11. For this sample about $15 \%$ of the observed MinTs were at or below the threshold. Verification results are shown in Table 5 for the 2015 frost season and are ranked by averaging the ETS for all forecast lead times available for each forecast model. Because Western Wx only provides a site-specific forecast at $15 \mathrm{~h}$, this value is included for ranking purposes. Note that Western Wx had access to the FFS forecasts for the entire frost season of 2015-the second full season of operation of the FFS. The author asked representatives of Western Wx if they monitored the FFS products discussed in the appendix, and they acknowledged that they did. Western $\mathrm{Wx}$ is sent nightly emails showing the verification of MinT, MaxT, and MinTw for the 40 sites. The email ranks the NDFDBC with the best model, the second best model, and the model that had the lowest accuracy for all lead times out to $168 \mathrm{~h}$-both for the previous day's forecast and the last 30 days. The models are ranked using the highest percentage of MinT, MaxT, 


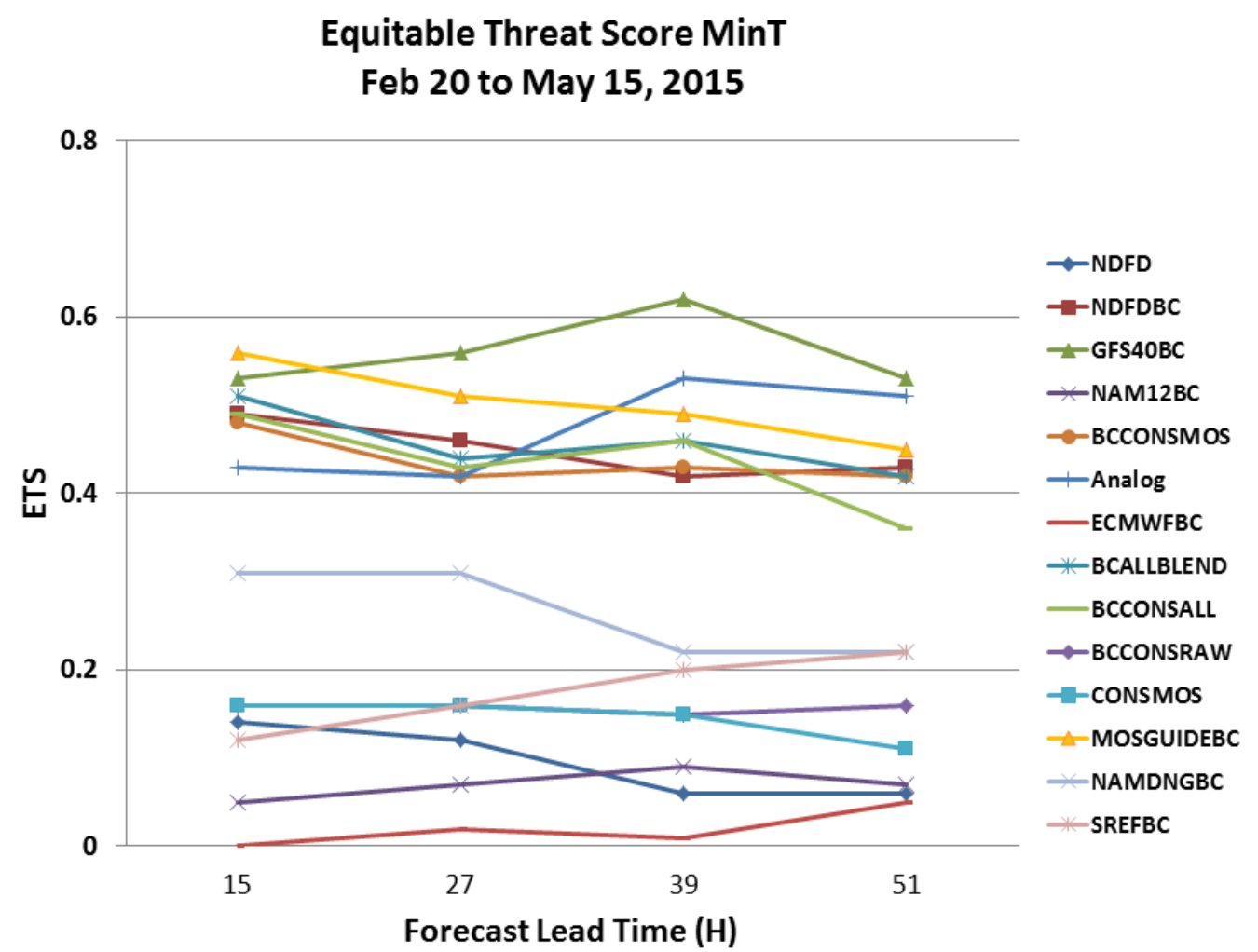

Figure 11. Equitable Threat Score as a function of forecast lead time for daily $\operatorname{MinT} \leq 2^{\circ} \mathrm{C}$ for the period 20 February-May 2015 for 40 vineyard sites.

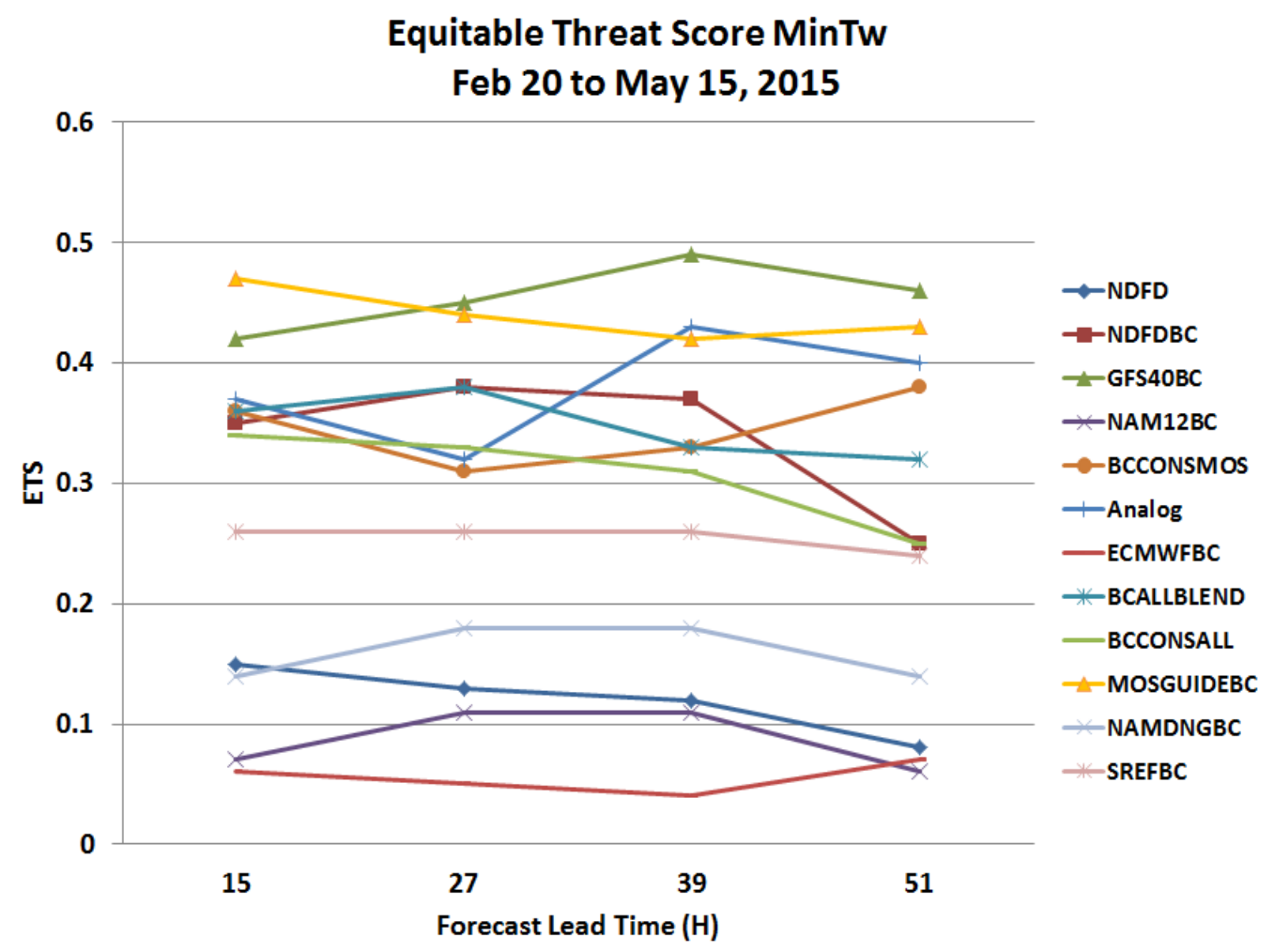

Figure 12. Equitable Threat Score for forecast MinTw as per Fig. 11 for MinT using the same $\leq 2{ }^{\circ} \mathrm{C}$ threshold. 
Table 5. Equitable Threat Score for MinT $\leq 2^{\circ} \mathrm{C}$ versus forecast lead time. A -999.00 indicates no forecast available for that lead time. The average ETS is used to rank the forecasts.

\begin{tabular}{|c|c|c|c|c|c|}
\hline Forecast lead time $\rightarrow$ & $15 \mathrm{~h}$ & $27 \mathrm{~h}$ & $39 \mathrm{~h}$ & $51 \mathrm{~h}$ & Average \\
\hline Western Wx & 0.36 & -999.00 & -999.00 & -999.00 & 0.36 \\
\hline GFS40BC & 0.30 & 0.34 & 0.39 & 0.35 & 0.35 \\
\hline ADJECSBC & 0.30 & 0.32 & 0.30 & 0.28 & 0.30 \\
\hline ADJMEX & -999.00 & 0.27 & 0.30 & 0.32 & 0.30 \\
\hline Analog & 0.25 & 0.34 & 0.32 & 0.25 & 0.29 \\
\hline BCCONSMOS & 0.28 & 0.23 & 0.25 & 0.26 & 0.26 \\
\hline ADJMAV & 0.17 & 0.27 & 0.30 & 0.27 & 0.25 \\
\hline ADJMEXBC & -999.00 & 0.27 & 0.25 & 0.21 & 0.24 \\
\hline ADJMAVBC & 0.20 & 0.26 & 0.30 & 0.17 & 0.23 \\
\hline MOSGuideBC & 0.17 & 0.23 & 0.23 & 0.24 & 0.22 \\
\hline ADJMETBC & 0.25 & 0.21 & 0.17 & 0.20 & 0.21 \\
\hline ADJMET & 0.24 & 0.21 & 0.13 & 0.14 & 0.18 \\
\hline SREFBC & 0.12 & 0.16 & 0.20 & 0.22 & 0.18 \\
\hline WModel & 0.17 & 0.27 & 0.13 & 0.11 & 0.17 \\
\hline CONSMOS & 0.17 & 0.19 & 0.13 & 0.15 & 0.16 \\
\hline BCCONSAII & 0.21 & 0.17 & 0.19 & 0.03 & 0.15 \\
\hline SREFBC & 0.12 & 0.16 & 0.20 & 0.10 & 0.15 \\
\hline NDFDBC & 0.20 & 0.19 & 0.11 & 0.08 & 0.15 \\
\hline BCAllBlend & 0.21 & 0.14 & 0.12 & 0.06 & 0.13 \\
\hline ADJECS & 0.08 & 0.15 & 0.14 & 0.13 & 0.13 \\
\hline HIRESWarwBC & 0.08 & 0.03 & 0.14 & -999.00 & 0.08 \\
\hline GFS40 & 0.03 & 0.04 & 0.10 & 0.15 & 0.08 \\
\hline NDFD & 0.12 & 0.12 & 0.01 & 0.01 & 0.07 \\
\hline NAM12BC & 0.08 & 0.03 & 0.02 & 0.05 & 0.05 \\
\hline BCCONSRaw & 0.07 & 0.03 & 0.03 & 0.02 & 0.04 \\
\hline ECMWFBC & 0.01 & 0.02 & 0.03 & 0.01 & 0.02 \\
\hline ALLBLEND & 0.05 & 0.00 & 0.00 & 0.00 & 0.01 \\
\hline NAM12 & 0.00 & 0.00 & 0.00 & 0.00 & 0.00 \\
\hline ECMWF & 0.00 & 0.00 & 0.00 & 0.00 & 0.00 \\
\hline CONSALL & 0.00 & 0.00 & 0.00 & 0.00 & 0.00 \\
\hline CONSRAW & 0.00 & 0.00 & 0.00 & 0.00 & 0.00 \\
\hline MOSGuide & 0.00 & 0.00 & 0.00 & 0.00 & 0.00 \\
\hline SREF & 0.00 & 0.00 & 0.00 & 0.00 & 0.00 \\
\hline HIRESWnmmBC & 0.00 & 0.00 & 0.00 & -999.00 & 0.00 \\
\hline HIRESWnmm & 0.00 & 0.00 & 0.00 & -999.00 & 0.00 \\
\hline NAMDNG & 0.00 & 0.00 & 0.00 & -0.03 & -0.01 \\
\hline HIRESWarw & -0.01 & -0.01 & -0.01 & -999.00 & -0.01 \\
\hline
\end{tabular}

Table 6. Verification sites forecast by Western Weather for Sonoma County, CA.

\begin{tabular}{|l|c|c|c|}
\hline City & Latitude & Longitude & Elevation (m) \\
\hline Sebastopol & 38.419899 & -122.813004 & 29 \\
\hline Graton-South & 38.407398 & -122.858002 & 41 \\
\hline Geyserville-West & 38.706001 & -122.945999 & 79 \\
\hline Kenwood & 38.407622 & -122.541639 & 123 \\
\hline Sonoma-West & 38.2789 & -122.501999 & 37 \\
\hline Alexander Valley & 38.6754 & -122.824997 & 58 \\
\hline Forestville & 38.500702 & -122.875 & 33 \\
\hline Sonoma Valley & 38.429278 & -122.890853 & \\
\hline Santa Rosa Airport & 38.405253 & -122.798153 & \\
\hline Bennett Valley & 38.418697 & -122.660061 & \\
\hline Carneros & 38.223019 & -122.351617 & \\
\hline Dry Creek Valley & 38.684731 & -122.946056 & 9 \\
\hline
\end{tabular}


or MinTw having an MAE $<1.7^{\circ} \mathrm{C}$. Over time this should give Western $\mathrm{Wx}$ an appreciation of the FFS accuracy and what model(s) are consistently performing best.

The results show that the ETSs indicate less skill for these 12 sites than for the 40 sites shown in Fig. 11 . Note that only 7 of the 12 sites forecast by Western Wx provide real-time data that are accessible to the FFS. This certainly could impact the bias correction and the skill of the FFS at these sites. This highlights the fact that the FFS will produce a better forecast for locations in the FFS grid with real-time observations available. Although Western Wx is ranked at the top it should be noted that the GFS40BC has similar skill to Western Wx at 51-h lead time, and its overall average is very close to the $15-\mathrm{h}$ Western $\mathrm{Wx}$ forecast. The MOS adjusted guidance (ADJxxx) also is clustered near the top of the rankings along with the consensus bias-corrected MOS (BCCONSMOS). The Analog method also is ranked fairly high but may suffer by combining the raw GFS40 with the GFS40BC. Given the results from Fig. 11 and Table 5, it may be best to combine the best deterministic model, GFS40BC, with the best statistical guidance, BCCONSMOS or MOSGuideBC, as the models to average for the Analog technique. This will be tested during the 2016 frost season.

The verification of the FFS forecast of MinT and MinTw for the coldest mornings observed during the frost season of 2015 indicates that the bias-correction method using real-time vineyard observations provides a skillful forecast with several days of lead time and is comparable in skill to manually provided forecasts by the commercial vendor Western $\mathrm{Wx}$ for a subset of these locations at 15-h lead time. Comparison of the raw model forecasts versus the bias-corrected forecasts shows up to a factor of 3-4 increase in skill using the bias-correction method. In addition, there can be an improvement of several days in lead time of an impending frost event compared to the non-biascorrected guidance. As noted in the Introduction, it is useful to include information on the uncertainty of the forecast to provide the decision maker the level of confidence needed to be proactive in mitigating for possible frost damage. The appendix provides a description of the output products from the FFS that not only convey the expected value of MinT and MinTw, but also the number of models forecasting critical thresholds and the spread in the forecasted MinT or MinTw expected over the next five days.

\section{Summary and conclusions}

An all-digital and fully automated frost forecast system has been developed, prototyped, and converted to a fully functioning decision support system for use by commercial forecasters, vineyard operators, and water managers within the Russian River Basin of northern California. The system is based on the NWS GFE software; however, it requires no manual intervention other than monitoring for suspect surface observations not identified by the coarse objective quality control system. It utilizes a high-resolution terrain grid and a large number of real-time observations from vineyards and other weather stations available within the basin in an attempt to resolve the microclimates of individual vineyards. The system utilizes all available NCEP model and statistical guidance, as well as the official NWS forecasts from the San Francisco Bay and Eureka NWS WFOs obtained through the NDFD. All forecasts are bias corrected using a 30-day regression of observed versus forecast temperature and humidity. In addition to the NCEP numerical models and MOS guidance, the NWS CONS system has been applied, along with automating the Analog tool developed by the NWS.

The accuracy of the FFS was presented for forecasts of overnight MinTs during the 2014 and 2015 frost seasons utilizing 40 of the 72 vineyard observing sites. Although results shown should be considered preliminary, the FFS accuracy is comparable to other numerical, statistical, and manual forecast results noted in the literature with regard to forecasting overnight minimums. The use of bias correction shows that the day 2, and in some cases day 3, forecast is as good or better than the day 1 forecast using MAE as the measure of accuracy.

During the first two seasons of FFS operations (2014 and 2015) the occurrences of freezing to subfreezing morning minimums were well below average as indicated by two long-term climate stations located in the Russian River Valley. These stations indicated warming of extreme minimum temperatures with the occurrence of sub-freezing temperatures decreasing since the turn of the 20th century during the three months of spring normally considered the frost season for budding grapevines (March-May). To examine the skill of the FFS for the coldest overnight minimums, a threshold of observed MinT $\leq 2^{\circ} \mathrm{C}$ was used. This threshold had been used previously in Australia as a proxy for frost occurrence. For 2015 the frost season began almost a month early, which increased the 
percentage of observed overnight lows $\leq 2^{\circ} \mathrm{C}$ from $4 \%$ for the 2014 frost season to $15 \%$ for 2015 . The ETS was used as the measure of skill in forecasting these events (both for MinT and MinTw) as it takes into account the hits, misses, and false alarms - and penalizes for overforecasting the coldest events. Using the 40 vineyard sites for 2015, the GFS40BC showed significant skill in forecasting potential frost events even out at 51-h lead time and was by far the best numerical forecast guidance. At $15 \mathrm{~h}$ there was a cluster of numerical and statistical bias-corrected forecast guidance showing an ETS near 0.5, including the NDFDBC. This bias-corrected version of the NDFD showed more than a four-fold increase in skill over the non-bias-corrected NDFD received directly from the NWS. This highlights the benefit of utilizing the detailed terrain used in the FFS along with the benefit of having the real-time vineyard observations for bias correction. In fact, almost every guidance product's skill was improved by a factor of 3-4 over its non-bias-corrected version.

The FFS ETS scores for MinT $\leq 2{ }^{\circ} \mathrm{C}$ were compared to the Western Wx forecast using the 12 sites they use in their nightly forecast of overnight MinT. Only 7 of these 12 sites provide real-time observations to the FFS. Although the ETS scores were slightly lower for the 12 sites compared to the 40 sites discussed above, the best FFS guidance (GFS40BC) and several of the MOS-adjusted grids showed comparable skill even out at $51 \mathrm{~h}$ to Western Wx's 15 -h forecast. These results highlight the fact that the FFS will produce more skillful forecasts at locations where realtime observations are made available to the system.

The verification results discussed should be considered preliminary but encouraging and suggest how the FFS may perform in the future for forecasting both frost and heat events at site-specific vineyard locations. Although this paper focused on the frost forecast problem, the system is just as applicable to predicting summer heat and the resulting stress imposed on water supplies used both for irrigation and to reduce heat stress on the vines during the dry summer season. Verification of MaxT during the summer season, utilizing the prototype system and results from 2014 and a portion of 2015, indicate very similar skill-ETS values near 0.5 at $15-27$-h lead time for forecasting $\operatorname{MaxT} \geq 38^{\circ} \mathrm{C}$ (as has been shown for MinT $\leq 2^{\circ} \mathrm{C}$ ).

Users have various methods to receive or access the FFS forecasts. Partnering with Western Wx has allowed NOAA a vehicle to provide these forecasts directly to the growers. Both graphical displays of model forecasts and information contained in emails requested by users provide a measure of uncertainty and, therefore, attempt to provide the user the confidence needed to take action to prepare for a possible frost event. Because it is not possible on a day-by-day basis to know which model or models may perform best for tomorrow's forecast or the next 5-day forecast, over time it is hoped that the user utilizes these graphical and email services to make better informed decisions. The purpose of developing the FFS is not to compete with or replace the commercially provided frost forecasts but to enhance and improve their products and services. Recent comments utilizing the summer heat forecasts from the SCWA Chief Engineer stated "We are using the extreme temperature tool [FFS] to inform our reservoir operations during this drought as well as coordinating operations of our transmission system and the municipal water systems we provide water to. The agricultural community also is increasingly using the tool to plan their irrigation schedules especially around heat-wave events" (J. Jasperse 2015, personal communication). Ongoing verification and analysis along with user feedback will determine the utility of the FFS for both frost forecasts and heat events, both of which can impact stream flow and salmonid survival.

Finally, the techniques described here of obtaining site-specific observations to bias correct numerical and statistical forecast guidance to better forecast microclimates has broader application than just frost or heat forecasts. One can think of several different uses. One such application could be the use of state highway road and weather-observing stations to improve forecasts of hazardous winter road conditions and reduce these hazards by improved situational awareness. Many states have installed automated weather and road temperature observing systems to determine pavement conditions during winter for dispatching road crews for highway clearing and for determining the best road treatment solutions for the temperatures expected. One could envision obtaining this temperature information from the state's Department of Transportation (DOT) in real-time and, provided the GFE software is of sufficient resolution, improve temperature forecasts and lead times at critical highway locations - thus maximizing situational awareness of potential winter weather road hazards and improving road treatment to reduce these hazards. Because the GFE software is in the public domain, as is the numerical and statistical forecast guidance to populate the GFE, one could envision the state DOT, the NWS, or 
the private sector weather enterprise running an automated highway winter weather road forecast system based on the FFS method described in this paper.

Acknowledgments. This research was supported by the Sonoma County Water Agency. Special thanks to Jay Jasperse, Chief Engineer, who was instrumental in gaining interest and support from the wine-grower community. In addition, special thanks to FarmEcology Labs, Teraspase Inc., and Western Weather Group for their support in obtaining real-time vineyard observations. Special thanks to Western Weather Group for allowing web access to the FFS forecast. The authors thank Ron Miller, Tim Barker, and Jonathan Wolfe of the NWS for their expert technical support during the adaptation of the GFE and model spectrum software.

\section{APPENDIX}

\section{Output Products from the FFS}

Growers and commercial forecasters who are interested in receiving the frost forecasts have various means by which to do so. The web links that provide access to the various FFS output products are provided on the Western Weather/Sonoma County forecast page (westernwx.com/ sonoma). One of the most useful displays of the FFS is what is called the model spectrum page. This software was developed by an NWS forecaster (Wolfe 2011) for use by NWS offices to display site-specific forecasts for major cities within the office's county warning area (go.usa.gov/3XEHd). The system has been adapted for vineyard locations in the current study. Figure A1 is an example of the output for one vineyard. The main goal of this display is to provide the user with a level of confidence that would allow decisions to be made to prepare for possible critical temperatures within the next day or week.

In addition to these web displays, an automated email notification system has been developed for SCWA and their water contractors. Email notifications are disseminated when critical temperatures are forecast over the next $24 \mathrm{~h}$ and/or 5 days. The threshold used for triggering an email is $1^{\circ} \mathrm{C}$. These emails provide the user with the number of models that forecast the event, as well as the specific forecast from the highest ranked model (the model that had the best 15 -h forecast from the day before). In addition, a link is provided to the model spectrum page that plots all the models' forecasts for their location for the next five days. Again, the purpose of this display is to provide the user with the degree of uncertainty associated with the forecast for the following day or the next five days. Based on user feedback, the emails are the least intrusive and most useful method of notification of possible critical tempertures occurring at specific locations in the next $24-120 \mathrm{~h}$.

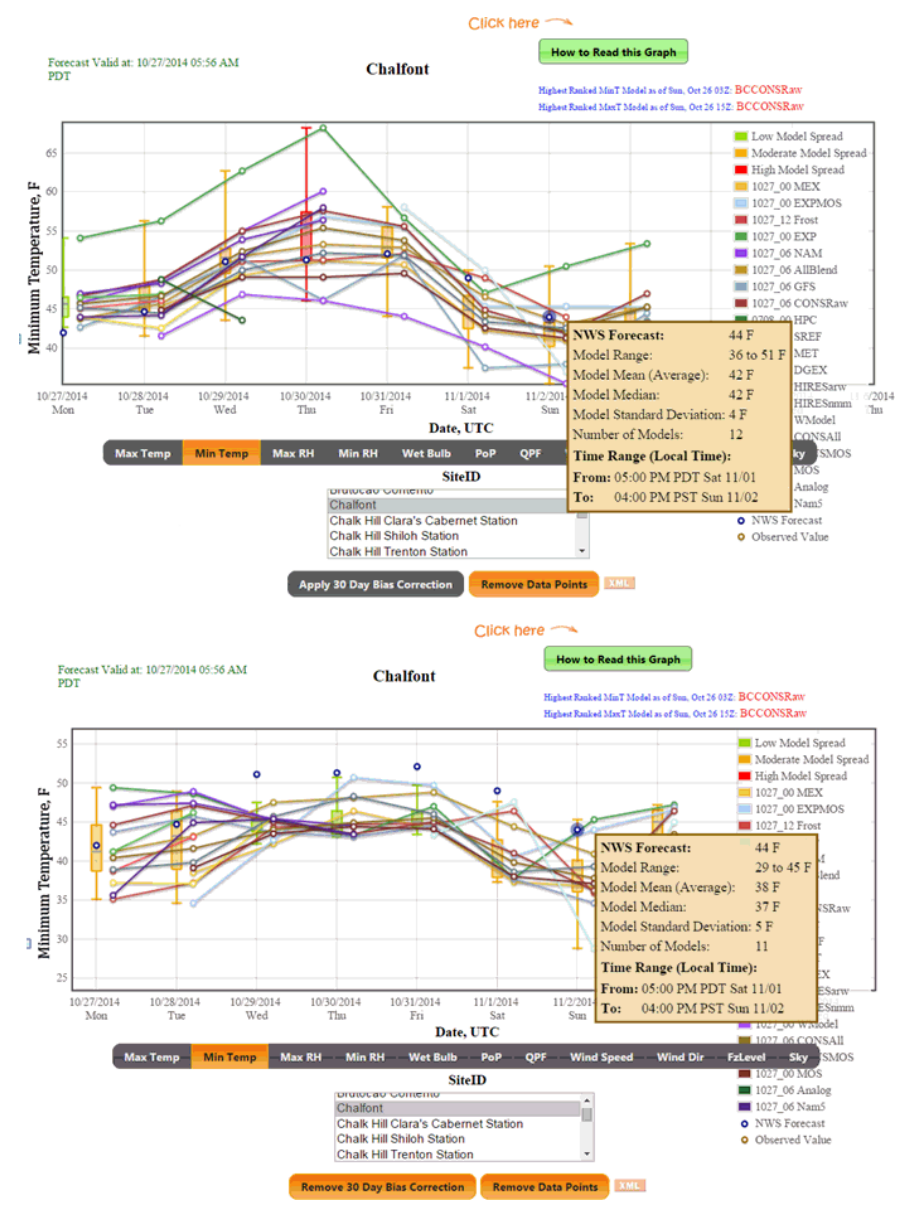

Figure A1. Model spectrum display showing the raw or non-biascorrected model forecasts (top figure) the application of the 30-day bias regression correction (bottom figure). See Wolfe (2011) for details.

\section{REFERENCES}

Colin, L. R., 2006: Using BOI_Verify to identify model preferences in large temperature-change events. Preprints, 22nd Conf. on Weather Analysis and Forecasting and 18th Conf. on Numerical Weather Prediction, Park City, UT, Amer. Meteor. Soc., P2.36. [Available online at ams.confex.com/ams/pdfpapers/ 123776.pdf.]

Craven, J. P., J. Wiedenfeld, J. Gagan, P. Browning, A. Just, and C. Grief, 2013: The NWS Central Region extended forecast process. Preprints, 38th Annual Meeting, Charleston, SC, Natl. Wea. Assoc., 5 pp. [Available online at www.nwas.org/meetings/nwa2013/extended abstracts/NWA2013 P2.38 Craven etal.pdf.]

Davis, J. T., 2004: Bias removal and model consensus forecasts of maximum and minimum temperatures using the graphical forecast editor. NOAA/NWS/WR Tech. Attach. 04-10, 13 pp. [Available online at 
www.wrh.noaa.gov/media/wrh/online_publications/TA s/ta0410.pdf.]

De Pondeca, M. S. F. V., and Coauthors, 2011: The RealTime Mesoscale Analysis at NOAA's National Centers for Environmental Prediction: Current status and development. Wea. Forecasting, 26, 593-612, CrossRef.

Engel, C., and E. E. Ebert, 2012: Gridded operational consensus forecasts of 2-m temperature over Australia. Wea. Forecasting, 27, 301-322, CrossRef.

Foisy, T., 2003: The MatchObsAll analysis system. NOAA/ NWS WR Tech. Attach. 03-02, 12 pp. [Available online at www.wrh.noaa.gov/media/wrh/online_publications/ TAs/ta0302.pdf.]

Gershunov, A., T. P. Barnett, and D. R. Cayan, 1999: North Pacific interdecadal oscillation seen as factor in ENSOrelated North American climate anomalies. Eos, 80, 2530, CrossRef.

Glahn, B., 2012: Bias correction of MOS temperature and dewpoint forecasts. MDL Office Note 12-1. National Weather Service, Office of Science and Technology, Meteorological Development Laboratory, Silver Spring, MD, 35 pp. [Available online at www.nws.noaa.gov/ mdl/pubs/Documents/OfficeNotes/MDL_OfficeNote12 -1.pdf.]

, and D. A. Lowry, 1972: The use of model output statistics (MOS) in objective weather forecasting. $J$. Appl. Meteor., 11, 1203-1211, CrossRef.

, and D. P. Ruth, 2003: The new digital forecast database of the National Weather Service. Bull. Amer. Meteor. Soc., 84, 195-201, CrossRef.

Horel, J. M., and Coauthors, 2002: Mesowest: Cooperative mesonets in the western United States. Bull. Amer. Meteor. Soc., 83, 211-225, CrossRef.

Jenks, E., J. Estupiñán, and A. Kennedy, 2012: Performance of gridded maximum and minimum temperature guidance and forecasts at the National Weather Service's Miami forecast office. Preprints, 37th Annual Meeting, Madison, WI, Natl. Wea. Assoc., 30 pp. [Available online at www.nwas.org/meetings/nwa2012/ extendedabstracts/NWA2012_P1.44_Estupinan_etal.pdf.]

Kala, J., T. J. Lyons, I. J. Foster, and U. S. Nair, 2009: Validation of a simple steady-state forecast of minimum nocturnal temperatures. J. Appl. Meteor. Climatol., 48, 624-633, CrossRef.

Katz, R. W., A. H. Murphy, and R. L. Winkler, 1982: Assessing the value of frost forecasts to orchardists: A dynamic decision-making approach. J. Appl. Meteor., 21, 518-531, CrossRef.

LeFebvre, T. J., 1995: Operational forecasting with AFPS. Preprints, 11th Int. Conf. on Interactive Information and Processing Systems for Meteorology, Oceanography, and Hydrology, Dallas, TX, Amer. Meteor. Soc., 249-254. [Available online at gfesuite.noaa.gov/ publications/papers/IIPS/Tom95/TomPaper95.html.]

, M. Romberg, T. Hansen, 2002: Initializing gridded fields from numerical models. Preprints, Interactive
Symp. on the Advanced Weather Interactive Processing System (AWIPS), Orlando, FL, Amer. Meteor. Soc., 4145. [Available online at gfesuite.noaa.gov/publications/ papers/IIPS/2002/InitGriddedFields.pdf.]

Lhomme, J. P., and L. Guilioni, 2004: A simple model for minimum crop temperature forecasting during nocturnal cooling. Agric. For. Meteorol., 123, 55-68, CrossRef.

Mason, I., 2003: Binary events. Forecast Verification: A Practitioner's Guide in Atmospheric Science, I. T. Jolliffe and D. B. Stephenson, Eds., Wiley, 37-76.

Mass, C. F., 2003: IFPS and the future of the National Weather Service. Wea. Forecasting, 18, 75-79, CrossRef.

, J. Baars, G. Wedam, E. Grimit, and R. Steed, 2008: Removal of systematic model bias on a model grid. Wea. Forecasting, 23, 438-459, CrossRef.

Myrick, D. T., and J. D. Horel, 2006: Verification of surface temperature forecasts from the National Digital Forecast Database over the western United States. Wea. Forecasting, 21, 869-892, CrossRef.

National Research Council, 2003: Fair Weather: Effective Partnerships in Weather and Climate Services. National Academies Press, 238 pp, CrossRef. , 2006: Completing the Forecast: Characterizing and Communicating Uncertainty for Better Decisions Using Weather and Climate Forecasts. The National Academies Press, 115 pp, CrossRef.

Roebber, P. J., 2010: Seeking consensus: A new approach. Mon. Wea. Rev., 138, 4402-4415, CrossRef.

Skamarock, W. C., and Coauthors, 2008: A description of the Advanced Research WRF Version 3. NCAR Tech. Note NCAR ITN-475 +STR, 125 pp. [Available online at www2.mmm.ucar.edu/wrf/users/docs/arw_v3.pdf.]

Snyder, R. L., and J. P. de Melo-Abreu, 2005: Frost Forecasting: Fundamentals, practices, and economics, Volume 1. Food and Agricultural Organization of the United Nations, 112 pp. [Available online at www.fao.org/docrep/008/y7223e/y7223e00.HTM.]

Thompson, P. D., 1977: How to improve accuracy by combining independent forecasts. Mon. Wea. Rev., 105, 228-229, CrossRef.

Wolfe, J. P., 2011: The model spectrum: A new approach to visualizing probabilistic weather forecasts. 6th Symp. on Policy and Socio-economic Research, Seattle, WA, Amer. Meteor. Soc., Poster 294. [Abstract available online at ams.confex.com/ams/91Annual/webprogram/ Paper177002.html.] 